\title{
Auditory Input Shapes Tonotopic Differentiation of Kv1.1 Expression in Avian Cochlear Nucleus during Late Development
}

\author{
(D)Nargis Akter, Ryota Adachi, Akitoshi Kato, Ryota Fukaya, and Hiroshi Kuba \\ Department of Cell Physiology, Nagoya University, Graduate School of Medicine, Nagoya 466-8550, Japan
}

Tonotopic differentiation is fundamental for signal processing in the auditory system. However, when and how this differentiation arises remain elusive. We addressed this issue using electrophysiology and immunohistochemistry in nucleus magnocellularis of chickens of both sexes, which is known to differ in the expression of Kv1.1 channels depending on characteristic frequency (CF). Just after hearing onset (embryonic day 12-14), Kv1 current gradually increased to a slightly larger extent in neurons with higher CF, causing a tonotopic difference of Kv1 current before hatch. However, after hatch, a much larger increase of Kvl current occurred, particularly in higher-CF neurons, due to an augmentation of Kv1.1 expression at the plasma membrane. This later change in expression led to the large tonotopic difference of Kv1 current characteristic of mature animals. Attenuation of auditory input by inducing conductive or sensorineural hearing loss around hatch suppressed the differentiation in a level-dependent manner. Moreover, elevation of auditory input during embryonic periods could not reproduce the differentiation, suggesting that the capacity of neurons to drive Kv1.1 expression via auditory input develops in a cell-specific manner, thus underlying the frequency-specific expression of the channel within the nucleus. The results indicated that the tonotopic differentiation of Kv1.1 in nucleus magnocellularis is partially determined before hatch, but largely driven by afferent input after hatch. Our results highlight the importance of neuronal capacity for sound to drive ion channel expression as well as the level of auditory experience in the frequency tuning of brainstem auditory circuits.

Key words: activity-dependent development; auditory; hearing loss; Kv1.1; tonotopy

Significance Statement

Tuning-frequency-specific expression of ion channels is a prerequisite for auditory system function, but its underlying mechanisms remain unclear. Here, we revealed in avian cochlear nucleus that the expression of Kv1.1 became more dependent on auditory input at a late period of maturation in neurons tuned to higher-frequency sound, leading to frequency-specific Kv1.1 expression. Attenuation of auditory input during this period suppressed the differentiation in a level-dependent manner, whereas elevation of input in earlier periods could not reproduce the differentiation. Thus, the capacity of neurons to drive Kv1.1 expression via auditory input develops in a cell-specific manner and directs differentiation, highlighting the importance of neuronal character as well as the level of input in the frequency tuning of auditory circuits.

\section{Introduction}

Tonotopic organization is a topographic representation of sound frequency in the auditory pathway, where neurons tuned to a

Received Aug. 29, 2017; revised Jan. 30, 2018; accepted Feb. 5, 2018.

Author contributions: N.A. and H.K. designed research; N.A., R.A., A.K., R.F., and H.K. performed research; R.F. contributed unpublished reagents/analytic tools; N.A., R.A., A.K., and H.K. analyzed data; N.A., R.A., R.F., and H.K. wrote the paper.

This work was supported by Ministry of Education, Culture, Sports, Science and Technology Grant-in-aid 15 H04257 to H.K. and Grant-in-aid 16K07345 to R.A., and a Grant on Innovative Areas Dynamic regulation of Brain Function by Scrap \& Build 17 H05742 to H.K. N.A. was supported by a Ministry of Education, Culture, Sports, Science and Technology scholarship. R.F. was supported by the Takeda Science Foundation Fellowship.

The authors declare no competing financial interests.

Correspondence should be addressed to Dr. Hiroshi Kuba, Department of Cell Physiology, Nagoya University, Graduate School of Medicine, Nagoya 466-8550, Japan. E-mail: kuba@med.nagoya-u.ac.jp.

DOI:10.1523/JNEUROSCI.2472-17.2018

Copyright $\odot 2018$ the authors $\quad 0270-6474 / 18 / 382967-14 \$ 15.00 / 0$ specific frequency (characteristic frequency $[\mathrm{CF}]$ ) are arranged in an orderly fashion according to their CF. This representation is primarily created in the position in the basilar membrane at the cochlea and preserved along the auditory pathway via topological wiring of neurons. Moreover, it has become clear that auditory neurons are not only wired to a specific frequency region of the cochlea but are also differentiated morphologically and biophysically in a region-specific manner (Kuba, 2007). Auditory experience is considered crucial in the establishment of these differentiations (Leao et al., 2006). However, when and how auditory inputs contribute to the tonotopic differentiations of auditory neurons during development remains unclear.

The nucleus magnocellularis (NM) is a good model to address this issue because the tonotopic differentiations of neurons in the nucleus have been characterized extensively (Fukui and Ohmori, 
2004; Kuba and Ohmori, 2009; Oline et al., 2016). NM neurons receive synaptic inputs from the auditory nerve (see Fig. 1A) and generate spikes at a specific phase of sound (phase lock), thereby conveying the temporal information of sound to higher auditory centers (Trussell, 1999). Two types of voltage-gated $\mathrm{K}^{+}(\mathrm{Kv})$ channels, Kv1.1 and Kv3.1, are predominantly expressed in NM neurons (Reyes et al., 1994; Rathouz and Trussell, 1998; Parameshwaran et al., 2001; Fukui and Ohmori, 2004). Kv1.1 has a low activation voltage and improves the phase locking of spikes by suppressing burst firing during synaptic inputs. On the other hand, Kv3.1 has a high activation voltage and promotes high-frequency firing through accelerating the falling phase of action potentials. Kv1.1 is differentiated in its expression along the tonotopic axis and increases toward the high-CF region, which enables individual NM neurons to respond to patterns of synaptic inputs characteristic of their CF (Fukui and Ohmori, 2004). The expression of Kv1.1 is affected by auditory inputs in the NM of mature animals ( $\mathrm{Lu}$ et al., 2004; Kuba et al., 2015), suggesting that sensory experience regulates the maturation of Kv1.1 in NM during development.

In this study, we characterized the development of Kv1.1 and Kv3.1 expression in high- and low-CF regions in the NM of chickens and examined their dependence on afferent inputs. We found that a tonotopic difference of Kv1.1 expression appeared after hearing onset, but this difference was small during the embryonic period. However, the Kv1.1 expression increased greatly after hatch specifically in higher-CF regions, largely creating the differentiation of the channel within the nucleus. The increase in Kv1.1 was disturbed by the attenuation of auditory inputs in hatchlings, implying that the dependence of Kv1.1 expression on auditory inputs was augmented around hatch and was more prominent in higher-CF regions. The results suggested that NM neurons differ tonotopically in their capacity for sound to drive Kv1.1 expression within the nucleus.

\section{Materials and Methods}

Animals. Chickens (Gallus domesticus) of either sex between embryonic day 12 (E12) and posthatch day 11 (P11) were used for electrophysiology and immunohistochemistry. The experimental animals' care was in accordance with the Regulations on Animal Experiments in Nagoya University. The developmental stages of the embryos followed the Hamburger and Hamilton (1951) series.

Tonotopic regions of the NM. Neurons in the high- and low-CF regions were used in most experiments. The high-CF region was defined as the rostromedial one-third of the $\mathrm{NM}$, and the low-CF region as the caudolateral one-third, including the lateral part of the caudal region and the caudal pole of the NM (see Fig. 1B) (Fukui and Ohmori, 2004; Kuba and Ohmori, 2009). The low-CF region would correspond to the lowfrequency area of the NM (NMc) in Wang et al. (2017), where neurons are heterogeneous in chemical as well as morphological and biophysical features. There is a clear relationship between CF and position in the NM of late embryos and posthatch chicks (Rubel and Parks, 1975; Lippe and Rubel, 1985), but the relationship in early embryos is unknown. Therefore, the CF used here is a relative measure in each age and has no relation to the absolute sound frequency.

Slice preparation. Brain slices were prepared as described previously (Kuba et al., 2015). Embryos were anesthetized by cooling eggs in icecold water, and chicks were deeply anesthetized with ether (Nacalai). After decapitation, the brainstem was isolated and submerged in an icecold high-glucose ACSF (concentration in mM as follows: $75 \mathrm{NaCl}, 2.5$ $\mathrm{KCl}, 26 \mathrm{NaHCO}_{3}, 1.25 \mathrm{NaH}_{2} \mathrm{PO}_{4}, 1 \mathrm{CaCl}_{2}, 3 \mathrm{MgCl}_{2}, 100$ glucose), saturated with $95 \% \mathrm{O}_{2}$ and $5 \% \mathrm{CO}_{2}$. The brainstem was embedded in a $3.5 \%$ (w/v) agarose gel (Nacalai), and three to six coronal slices (200-230 $\mu \mathrm{m})$ were cut with a tissue slicer (VT1200, Leica). The slices were incubated in high-glucose ACSF at room temperature for $\sim 30$ min before use.

Electrophysiology. Current and voltage-clamp recordings were made as described previously (Kuba et al., 2015). Slices were perfused with an
ACSF (concentrations in mM as follows: $125 \mathrm{NaCl}, 2.5 \mathrm{KCl}, 26 \mathrm{NaHCO}_{3}$, $1.25 \mathrm{NaH}_{2} \mathrm{PO}_{4}, 2 \mathrm{CaCl}_{2}, 1 \mathrm{MgCl}_{2}$, and 17 glucose). Current-clamp recordings were made at $37-38^{\circ} \mathrm{C}$ with a $\mathrm{K}^{+}$-based internal solution (in mM as follows: $113 \mathrm{~K}$-gluconate, $4.5 \mathrm{MgCl}_{2}, 0.1 \mathrm{EGTA}, 14 \mathrm{Tris}_{2}$-phosphocreatine, 4 $\mathrm{Na}_{2}$-ATP, 0.3 Tris-GTP, 9 HEPES-KOH, pH 7.2). Voltage-clamp recordings were made at $20^{\circ} \mathrm{C}$ with a $\mathrm{Cs}^{+}$-based internal solution (in mM as follows: $155 \mathrm{CsMeSO}_{3}, 5 \mathrm{NaCl}, 3 \mathrm{MgCl}_{2}, 0.2 \mathrm{EGTA}, 10 \mathrm{HEPES}-\mathrm{CsOH}$, $\mathrm{pH}$ 7.2), whereas $\left[\mathrm{K}^{+}\right]_{\mathrm{o}}$ was increased to $5 \mathrm{~mm},\left[\mathrm{Ca}^{2+}\right]_{\mathrm{o}}$ decreased to 0.5 $\mathrm{mm}$, and $\mathrm{Cd}^{2+}(0.2 \mathrm{~mm}), \mathrm{Ni}^{2+}(0.5 \mathrm{~mm})$, and TTX ( $1 \mu \mathrm{M}$, Tocris Bioscience) were added to the bath. The $\mathrm{Cs}^{+}$-based internal solution and the lower recording temperature reduced and slowed potassium currents substantially, which minimized series resistance errors and allowed accurate recordings in the neurons (Rathouz and Trussell, 1998; Kuba et al., 2015). Kv1 current was also measured with the $\mathrm{K}^{+}$-based internal solution under the blockade of $\mathrm{Kv} 3$ current (tetraethylammonium [TEA], 1-3 mM) in E21 and P3-P5. Excitatory and inhibitory synaptic inputs were blocked with DNQX (20 $\mu \mathrm{M}$, Tocris Bioscience) and SR95531 (10 $\mu \mathrm{M}$, Tocris Bioscience) in the bath. Liquid junction potentials were corrected: $11.6 \mathrm{mV}$ for current clamp and $7.0 \mathrm{mV}$ for voltage clamp. Patch pipettes had a resistance of 3-4 M $\Omega$, and the series resistance was compensated electronically up to $80 \%$. Voltage-dependent activation of the potassium current was analyzed by plotting the amplitude of the tail current after normalization and fitting the curve with a double Boltzmann equation (Rathouz and Trussell, 1998; Kuba et al., 2015) as follows: $\mathrm{I} / \mathrm{I}_{\max }=\mathrm{A} 1 /\left\{1+\exp \left[-\left(\mathrm{V}_{\mathrm{m}}-\mathrm{V}_{1 / 2} 1\right) / \mathrm{S} 1\right]\right\}+\mathrm{A} 2 /\{1+$ $\left.\exp \left[-\left(\mathrm{V}_{\mathrm{m}}-\mathrm{V}_{1 / 2} 2\right) / \mathrm{S} 2\right]\right\}$, where $\mathrm{I}$ is the tail current amplitude, $\mathrm{I}_{\max }$ is the maximum tail current amplitude, $\mathrm{V}_{\mathrm{m}}$ is the membrane potential, $\mathrm{Al}$ and $A 2$ are weighting factors, $V_{1 / 2} 1$ and $V_{1 / 2} 2$ are half-activation voltages, and $\mathrm{S} 1$ and $\mathrm{S} 2$ are slope factors of individual components. The currents were suppressed in the presence of $\mathrm{Kv} 1$ and $\mathrm{Kv} 3$ channel blockers $(0.1 \mu \mathrm{M}$ dendrotoxin and 1-10 mM TEA, respectively) in both embryos and posthatch chicks (Rathouz and Trussell, 1998; Kuba et al., 2015), implying that these channels are the major components of the potassium current in NM neurons. The decay phase of the tail current was fitted with a single exponential function for the $3 \mathrm{mV}$ prepulse. The potassium current density was calculated by normalizing the current to the membrane capacitance. Resting membrane parameters were measured by applying a depolarizing current (20-40 pA in embryos; $100 \mathrm{pA}$ in posthatch chicks) to the soma. Input resistance and resting conductance were measured at the pulse end, membrane time constant by fitting to a single exponential function, and membrane capacitance from the time constant and the input resistance. Spike parameters were analyzed as follows. Threshold current was measured as the minimum current required for spike induction, and threshold voltage as the voltage corresponding to an inflection point in the time derivatives of voltage. Latency was the time between the onset of current injection and threshold voltage, and measured at one step above threshold current. The spike number was counted at $800 \mathrm{pA}$.

Visualization of NM neurons. NM neurons at each CF region were visualized by introducing Alexa-594 hydrazide $(20 \mu \mathrm{M})$ under whole-cell condition, or Alexa-488 hydrazide (4 mM) with electroporation under loose-patch condition (see Fig. 1D) (Kuba et al., 2014). Slices were then fixed in 4\% PFA (in PBS) within $1 \mathrm{~h}$ at room temperature, mounted on a glass slide, and coverslipped. The slices were observed under a confocal microscope (FV1000, Olympus) with a $40 \times, 0.9 \mathrm{NA}$ objective. A series of images was captured at a step of $1.0-1.5 \mu \mathrm{m}$ and $Z$-stacked with a maximum intensity projection.

Immunohistochemistry. Immunohistochemical procedures were described previously (Kuba et al., 2015). In both embryonic and posthatch chickens, the brainstem was fixed without perfusion in a periodatelysine-PFA fixative [1\% (w/v) PFA, $2.7 \%(\mathrm{w} / \mathrm{v})$ lysine $\mathrm{HCl}, 0.21 \%(\mathrm{w} / \mathrm{v})$ $\mathrm{NaIO}_{4}$, and $\left.0.1 \%(\mathrm{w} / \mathrm{v}) \mathrm{Na}_{2} \mathrm{HPO}_{4} \cdot 12 \mathrm{H}_{2} \mathrm{O}\right]$ for $2 \mathrm{~h}$ at $4^{\circ} \mathrm{C}$. After cryoprotection with $30 \%(\mathrm{w} / \mathrm{w})$ sucrose, coronal sections of $30 \mu \mathrm{m}$ thickness were obtained with a cryostat (CM1950, Leica). Sections were incubated overnight at room temperature with primary antibodies (rabbit polyclonal Kv1.1 antibody, Alomone Labs, $1.5 \mu \mathrm{g} / \mathrm{ml}$; rabbit polyclonal Kv3.1b antibody, Sigma, $1.5 \mu \mathrm{g} / \mathrm{ml}$; mouse monoclonal PSD95 antibody, NeuroMab, $5 \mu \mathrm{g} / \mathrm{ml}$ ) and then with Alexa-conjugated secondary antibodies (Thermo Fisher Scientific) at room temperature for $2 \mathrm{~h}$ and observed under a confocal microscope (FV1000, Olympus). Images were 
captured from a single confocal plane with the same microscope setting for different ages and tonotopic regions. Cytosolic signals were measured within the soma $\left(>10 \mu \mathrm{m}^{2}\right)$ from $>20$ neurons in each animal with ImageJ (National Institutes of Health). Membranous signals were measured at the brightest region surrounding the soma $(>5 \mu \mathrm{m})$. Background signals were not different among ages and were not subtracted from the measurements.

Manipulations of auditory inputs. Auditory inputs in posthatch animals were attenuated monaurally via removing the tympanic membrane, fixing the middle ear bone (columella), or removing the cochlea around hatch under anesthesia with subcutaneous injection of chloral hydrate ( $160 \mathrm{mg} / \mathrm{kg}$, Nacalai) or pentobarbital (40 mg/kg, Nacalai) (Table 1) (Kuba et al., 2010, 2014). The tympanic membrane was removed via excising the membrane from the columella with fine scissors after opening the ear canal. Fixation of the columella was made via filling the middle ear with cyanoacrylate and spongel after removing the tympanic membrane. Cochlea removal was done with fine forceps after opening the tympanic membrane and oval window. Auditory inputs in embryos were attenuated via removing otocysts bilaterally at E2 (Stage 12 or 13), which completely eliminated both cochlea and auditory nerve bundles (Parks, 1981; Kuba et al., 2014). Auditory stimulation was applied between E17 and E21 for embryos and between P0 and P3 for posthatch animals. White noise $(100 \mathrm{~dB}, 57 \mathrm{~dB} / \mathrm{Hz})$ was generated and delivered with an iPad (Apple) and audio speakers (Z120BW, Logicool). The spectral power of the noise was weaker than that which induces cochlea damage in chickens (Cohen and Saunders, 1994). Attenuation of the noise by the shell and embryonic fluid was $11.3 \pm 1.3 \mathrm{~dB}$ when measured at the opposite side of the egg through the shell membrane after making a small hole in the shell for embryos between E18 and E21 (4 eggs). Animals were kept in a room with a noise level of $60 \mathrm{~dB}$, and eggs were kept in an incubator with a noise level of 60 or $80 \mathrm{~dB}$. The noise levels were measured with a noise meter (Type 6224, Aco).

Auditory evoked response recording. Auditory evoked potentials were recorded in 6 animals between $\mathrm{P} 1$ and $\mathrm{P} 3$ under anesthesia with subcutaneous injection of chloral hydrate $(160 \mathrm{mg} / \mathrm{kg})$ or pentobarbital $(40$ $\mathrm{mg} / \mathrm{kg}$ ). Surgical procedures were the same as those reported previously (Nishino et al., 2008). The contralateral columella was removed to avoid contamination of responses from the unstimulated ear. Stimulus frequency ranged between $0.5 \mathrm{kHz}$ and $3 \mathrm{kHz}$. Pulsed pure tone stimuli were presented with a $4 \mathrm{~ms}$ rise/fall time, a $20 \mathrm{~ms}$ duration, and an interstimulus interval of $300 \mathrm{~ms}$. The stimuli were made (RPvds, TDT), processed (RP2.1, TDT), attenuated (PA5, TDT), and delivered monaurally via a speaker (MF1, TDT) connected to a funnel fitted into the external auditory meatus. Calibration was made at the orifice of the funnel with a noise meter (Type 6224, Aco). Animals were fixed with a stereotaxic apparatus (SR-5M-HT, Narishige) in a soundproof box (Nishino et al., 2008). Evoked responses were recorded with needle electrodes implanted into left cerebellum at a level above NM (active), in right hippocampus (reference), and in neck muscle (ground). The responses were amplified, filtered at $10-3000 \mathrm{~Hz}$ (ER1, Cygnus Technology), digitized at $10 \mathrm{kHz}$ (PowerLab2/26, AD), and obtained from averages of 256 sweeps. Threshold was determined with a $5 \mathrm{~dB}$ step, and criterion of the threshold was twice the amplitude of baseline variation before stimulation (Saunders et al., 1973; Tucci and Rubel, 1985). Threshold measurements were repeated in each animal after attenuating auditory input via removing the tympanic membrane, fixing the columella, and removing the cochlea (Table 1).

Statistics. Statistical significance was determined with Student's $t$ test, unless otherwise stated. The level of statistical significance was set at 0.05 . Data are presented as the mean \pm SE $(n=$ number of cells $)$.

\section{Results}

Tonotopic differences in potassium conductance appeared after hearing onset

Whole-cell recordings were made from neurons at high- and low-CF regions of NM between E12 and P5 (Fig. 1 B, C; see Materials and Methods). The shapes of NM neurons conformed to those reported previously (Jhaveri and Morest, 1982; Wang et al.,
Table 1. Effects of conductive and sensorineural hearing loss on auditory evoked potential threshold (dB SPL) in posthatch animals ${ }^{a}$

\begin{tabular}{lclcc}
\hline & $0.5 \mathrm{kHz}$ & \multicolumn{1}{c}{$1 \mathrm{kHz}$} & \multicolumn{1}{c}{$2 \mathrm{kHz}$} & \multicolumn{1}{c}{$3 \mathrm{kHz}$} \\
\hline Control & $43.3 \pm 6.8$ & $32.5 \pm 5.5$ & $48.3 \pm 10.8$ & $64.2 \pm 10.8$ \\
Tymp rem & $78.3 \pm 7.0^{* *}$ & $65.8 \pm 6.9^{* *}$ & $79.2 \pm 9.6^{*}$ & $96.7 \pm 7.0^{*}$ \\
Colum fix & $101.7 \pm 1.7^{* *}$ & $97.5 \pm 4.8^{* *}$ & $101.7 \pm 7.6^{* *}$ & $106.7 \pm 5.2^{* *}$ \\
Coch rem & $>120$ & $>120$ & $>120$ & $>120$ \\
\hline
\end{tabular}

Tymp rem, Tympanic membrane removal; Colum fix, Columella fixation; Coch rem, Cochlea removal.

${ }^{a}$ Thresholds were measured in 6 animals between $\mathrm{P} 1$ and $\mathrm{P3}$ (see Materials and Methods).

${ }^{*} p<0.05$ compared with control; ** $p<0.01$ compared with control.

2017) (Fig. 1D). In the high-CF region, neurons had multiple primary dendrites before E15 but gradually lost them and became almost adendritic around E18; the number was $0.5 \pm 0.2(n=22)$ at E18 and $0(n=18)$ at P3-P5. In the low-CF region, on the other hand, neurons maintained multiple primary dendrites even after hatch; the number was $10.1 \pm 0.5(n=22)$ at E18 and $3.7 \pm 0.9$ $(n=18)$ at $\mathrm{P} 3-\mathrm{P} 5$. Voltage responses to somatic current injection developed differently between the high- and low-CF regions during the period (Fig. 1E). At E12, corresponding to hearing onset (E12-E14) (Saunders et al., 1973; Jones et al., 2006), both depolarizing $(800 \mathrm{pA})$ and hyperpolarizing $(-200 \mathrm{pA})$ currents caused large voltage responses in high-CF (left, blue) and low-CF (right, red) neurons (Fig. $1 B, E, F$ ). The depolarization generated one or a few spikes in the neurons (Fig. $1 G$ ), while the spikes showed a long latency (Fig. $1 H$ ) and required only a small current for induction (threshold current, gray, Fig. $1 E, I$ ), suggesting that the potassium conductance was still immature at that age. Indeed, the resting conductance was very small $(<3 \mathrm{nS})$, and the membrane potential was depolarized at E12 in both low- and high-CF neurons (Fig. 1J; Table 2). With development, the level of the voltage responses decreased, the threshold current increased, and the latency shortened (Fig. $1 E-I$ ). In addition, the resting conductance increased, and the membrane potential hyperpolarized (Fig. 1J; Table 2), indicative of an increase in the potassium conductance during the period. The extent of the changes was slightly larger in the high-CF neurons, resulting in some differences in the parameters among tonotopic regions. Correspondingly, the depolarizing currents generated multiple spikes until E15 but only a single spike after E18 in high-CF neurons, whereas they generated multiple spikes even after E21 in many of the low-CF neurons (Fig. 1E, G). These observations were consistent with the fact that membrane and firing properties are already differentiated between high- and low-CF neurons at E21 (Wang et al., 2017) (Table 2). Strikingly, however, a further increase in the potassium conductance occurred in both high- and low-CF neurons after hatch (P3-P5), as reflected in the increase in the threshold current and resting conductance (Fig. $1 \mathrm{I}, J$ ). More importantly, the extent of the increase was $\sim 2-3$ times larger in the higher CF neurons, and an injection of 800 pA could no longer generate a spike in the neurons. These results indicated that tonotopic differentiation of the potassium conductance is partially established during the embryonic period, but the differentiation is strongly augmented around the time of hatch in NM.

\section{Increase of Kvl current was accelerated after hatch in high- CF neurons}

We recorded the potassium current at $-77 \mathrm{mV}$ with voltage pulses between -107 and $13 \mathrm{mV}$ in NM neurons during development (Fig. 2). An outward current appeared during the test pulse (inset), and an inward tail current followed after termination of the pulse in both the high-CF (left, blue) and low-CF 
A

\section{C}
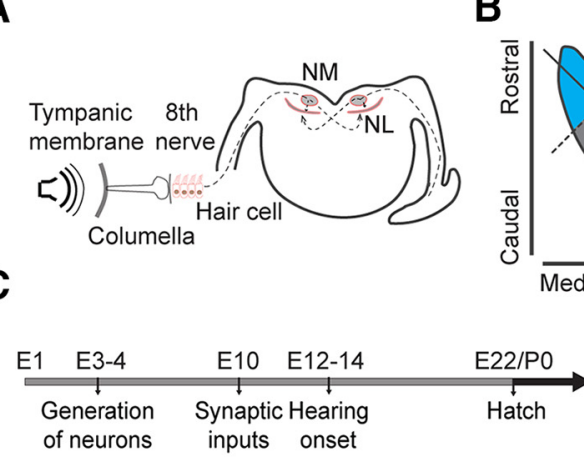

B

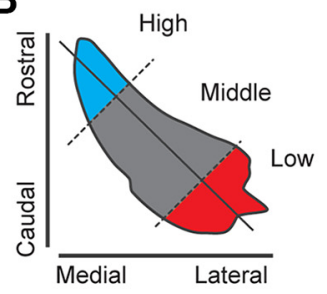

D

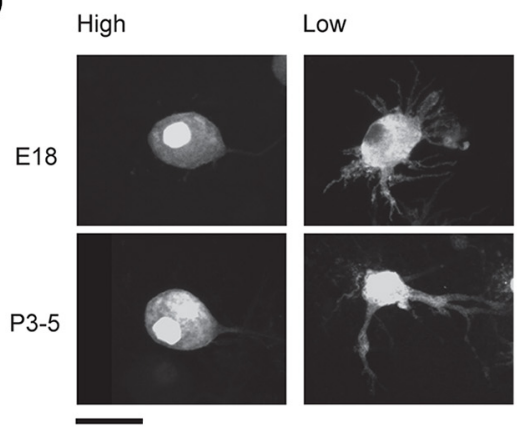

E
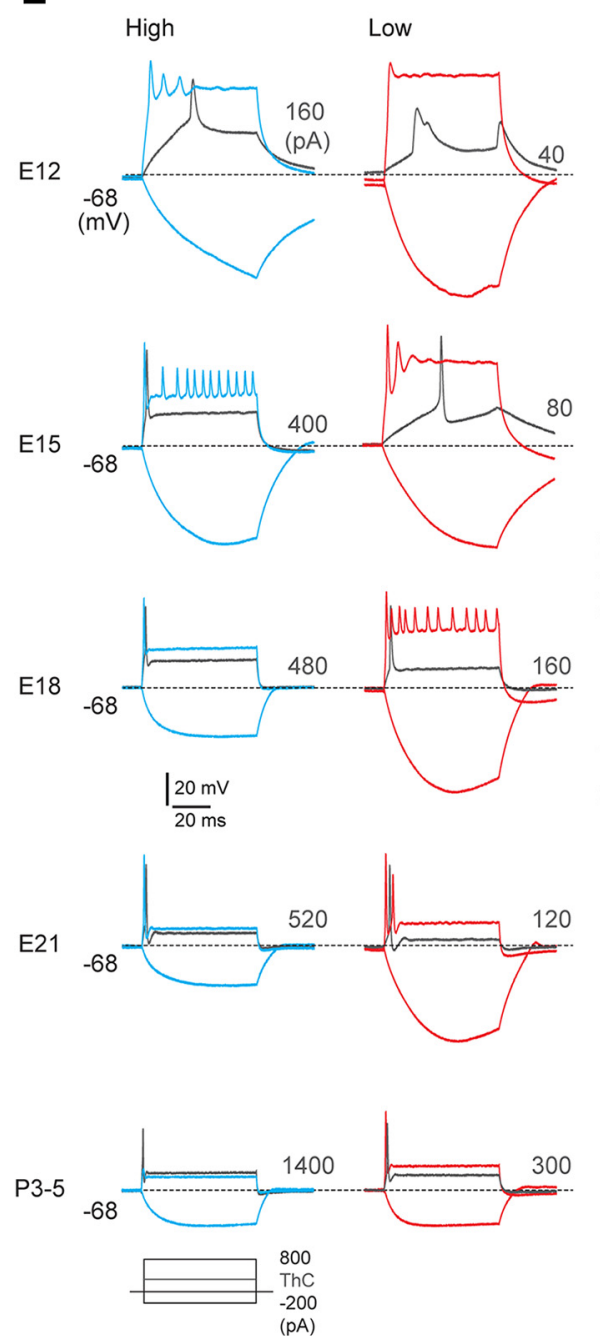

$\mathbf{F}$

F Injected current (pA)
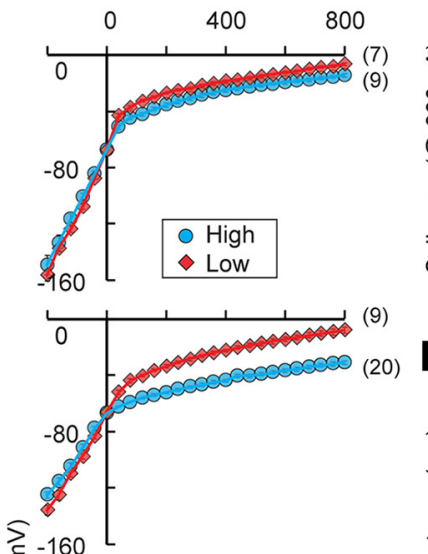

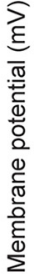

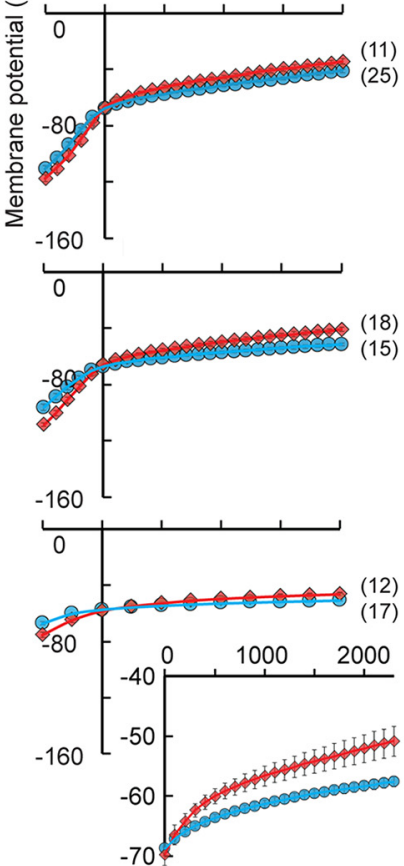

$(25)$
G
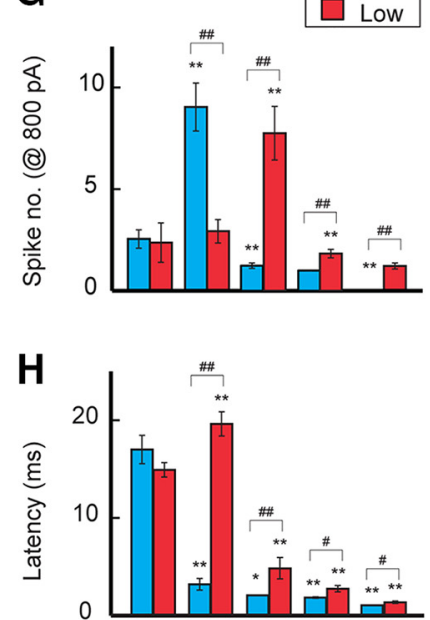
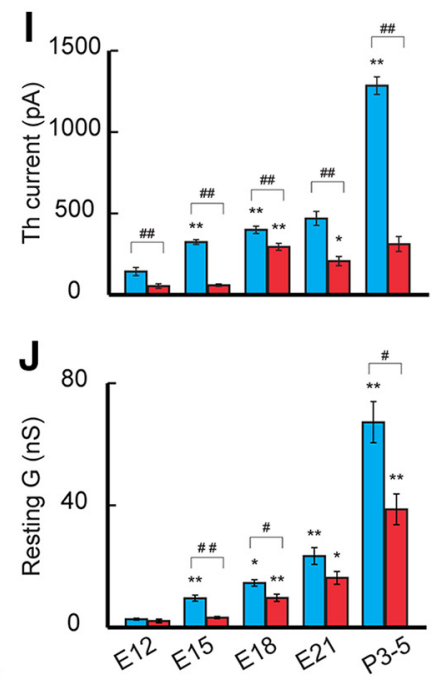

Figure 1. Development of voltage responses. $\boldsymbol{A}$, Schematic drawing of the avian auditory pathway, NL, nucleus laminaris. $\boldsymbol{B}$, Tonotopic regions were based on the position within the NM (see Materials and Methods). C, Time course of the development of the avian auditory system. D, NM neurons filled with dye in high- and low-CF regions. High-CF neurons were adendritic, whereas low-CF neurons had multiple primary dendrites at both ages. Scale bar, $20 \mu \mathrm{m}$. $E$, Voltage responses to somatic current injection in high-CF (left, blue) and low-CF (right, red) neurons between E12 and P3-P5. Current (70 ms) was increased from $-200 \mathrm{pA}$ to $800 \mathrm{pA}$ with a $40 \mathrm{pA}$ step in embryonic neurons and from $-200 \mathrm{pA}$ to $2300 \mathrm{pA}$ with a $100 \mathrm{pA}$ step in posthatch (P3-P5) neurons. The membrane potential was held at $-68 \mathrm{mV}$ by injecting current into the soma. Inset, Traces are shown for $-200 \mathrm{pA}, 800 \mathrm{pA}$, and threshold current (gray). Threshold current is specified at the right in each panel. Bursts of small spikes occurred at E15 for high-CF neurons and E18 for low-CF neurons, probably because spikes were generated in the distal axon due to the large depolarization. $\boldsymbol{F}$, Voltage-current relationship from $\boldsymbol{E}$. The posthatch high-CF neurons required $>1 \mathrm{nA}$ for spike generation. The entire current range is shown in the inset for posthatch neurons (bottom right). Numbers in parentheses are the number of cells. $\mathbf{G}-\boldsymbol{I}$, Parameters of spikes. Number $(\boldsymbol{G})$, latency $(\boldsymbol{H})$, and threshold current $(\boldsymbol{I})$ of spikes (see Materials and Methods). $\boldsymbol{J}$, Resting membrane conductance calculated at $20-40 \mathrm{pA}$ for embryo and $100 \mathrm{pA}$ for posthatch. ${ }^{\#} p<0.05$ and \#\#p $<0.01$ between tonotopic regions. ${ }^{*} p<0.05$ and ${ }^{* *} p<0.01$ compared with the neighboring younger group. 
Table 2. Membrane properties of NM neurons during development ${ }^{a}$

\begin{tabular}{|c|c|c|c|c|c|c|}
\hline Property & $C F$ & E12 & E15 & E18 & E21 & P3-5 \\
\hline \multirow{2}{*}{$V_{m}(m V)$} & High & $-53.6 \pm 1.4^{\# \#}$ & $-66.9 \pm 0.6^{* *, \# \#}$ & $-64.8 \pm 0.8^{\#}$ & $-65.2 \pm 0.7^{\#}$ & $-67.6 \pm 1.0$ \\
\hline & Low & $-45.2 \pm 1.1$ & $-56.2 \pm 1.2^{* *}$ & $-61.9 \pm 0.9^{* *}$ & $-61.8 \pm 1.1$ & $-63.0 \pm 1.4$ \\
\hline \multirow{2}{*}{$\mathrm{R}_{\mathrm{m}}(\mathrm{M} \Omega)$} & High & $460.2 \pm 38.4$ & $156.1 \pm 8.3^{* * \# \#}$ & $87.3 \pm 4.0^{* *, \# \#}$ & $59.1 \pm 3.6^{* *, \# \#}$ & $22.2 \pm 1.1^{* *, \# \#}$ \\
\hline & Low & $590.6 \pm 68.8$ & $405.5 \pm 26.2^{* *}$ & $158.9 \pm 12.4^{* *}$ & $93.2 \pm 7.8^{* *}$ & $39.8 \pm 7.5^{*}$ \\
\hline \multirow[t]{2}{*}{$\tau_{\mathrm{m}}(\mathrm{ms})$} & High & $32.9 \pm 4.2$ & $4.0 \pm 0.2^{* *, \# \#}$ & $1.8 \pm 0.1^{* *, \# \#}$ & $1.3 \pm 0.1^{* *, \# \#}$ & $0.6 \pm 0.1^{* *}$ \\
\hline & Low & $27.6 \pm 3.3$ & $27.6 \pm 1.9$ & $5.9 \pm 1.0^{* *}$ & $3.0 \pm 0.5^{*}$ & $1.2 \pm 0.2^{*}$ \\
\hline \multirow[t]{2}{*}{$C_{m}(p F)$} & High & $71.1 \pm 5.6^{\# \#}$ & $24.7 \pm 1.0^{* *, \# \#}$ & $21.4 \pm 0.8^{\# \#}$ & $22.0 \pm 2.0$ & $24.9 \pm 2.0$ \\
\hline & Low & $46.7 \pm 1.9$ & $68.5 \pm 2.1^{* *}$ & $35.0 \pm 3.3^{* *}$ & $34.9 \pm 9.0$ & $31.2 \pm 2.5$ \\
\hline
\end{tabular}

${ }^{a} \mathrm{~V}_{\mathrm{m}}$, Resting membrane potential; $\mathrm{R}_{\mathrm{m}}$, input resistance; $\tau_{\mathrm{m}}$, membrane time constant; $\mathrm{C}_{\mathrm{m}}$, membrane capacitance.

${ }^{*} p<0.05$ and ${ }^{* *} p<0.01$ compared with the neighboring younger group.

$\# p<0.05{ }^{\# \#} p<0.01$ between tonotopic regions.

(right, red) neurons (Fig. 2A). At E12, the tail current was small and did not differ in amplitude between the high- and low-CF neurons (Fig. $2 B, F$ ). In addition, when the activation curve was fitted with a double Boltzmann equation (see Materials and Methods), the curve was mostly composed of the Kv3 component with a half-activation voltage $\left(\mathrm{V}_{1 / 2}\right)$ of $\sim-20 \mathrm{mV}(>99 \%)$, and the $\mathrm{Kv} 1$ component $\left(\mathrm{V}_{1 / 2}\right.$ of $\left.\sim-60 \mathrm{mV}\right)$ was almost absent (Fig. 2C), suggesting that the potassium current was still immature and not tonotopically differentiated at that age. After E12, the potassium current became larger (Fig. $2 B, F$ ), with a substantial Kv1 component (Fig. 2C,D), suggestive of the appearance of the Kv1 current after hearing onset. Notably, the increases in both the $\mathrm{Kv} 1$ and Kv3 currents were slightly larger in higher CF neurons, causing some tonotopic differences in the currents during the embryonic period (Fig. 2D,E). Nevertheless, the increase in the Kv1 current was small, and its tonotopic difference was still moderate even at E21.

The gradual increase in the Kv1 current in embryos contrasted with a sharp increase in Kv1 current after hatch, as was reflected in the increase of the tail current at $-42 \mathrm{mV}$ (Fig. $2 A, B$, arrows). Moreover, the increase was much larger in high-CF neurons than in low-CF neurons (Fig. 2C,D). Indeed, pharmacologically isolated Kv1 current, which was measured with TEA (1-3 mM) in the bath, was $1.1 \pm 0.1 \mathrm{nA}(n=11)$ and $4.3 \pm 0.2 \mathrm{nA}(n=10)(p=$ $\left.7.1 \times 10^{-12}\right)$ at E21 and P3-P5, respectively, in high-CF neurons, whereas it was $0.6 \pm 0.1 \mathrm{nA}(n=7)$ and $1.3 \pm 0.2 \mathrm{nA}(n=7)(p=$ 0.003 ) in low-CF neurons. Outward Kv1 current measured with the $\mathrm{K}^{+}$-based internal solution (see Materials and Methods) also showed similar results; the amplitude at pulse end $(-32 \mathrm{mV})$ was $1.2 \pm 0.2 \mathrm{nA}(n=6)$ and $4.5 \pm 0.4 \mathrm{nA}(n=7)\left(p=1.6 \times 10^{-5}\right)$ at E21 and P3-P5, respectively, in high-CF neurons, whereas it was $0.4 \pm 0.1 \mathrm{nA}(n=8)$ and $1.1 \pm 0.3 \mathrm{nA}(n=8)(p=0.02)$ in low-CF neurons. In contrast, the Kv3 current decreased after E21, which eliminated the tonotopic difference in the Kv3 current in posthatch neurons (Fig. 2C,E). Accordingly, the Kv1 current became dominant in high-CF neurons, causing a large tonotopic difference in the Kv1 current in mature animals. The tendency was the same when evaluated with current density (see Materials and Methods), showing an increase of $171 \mathrm{pA} / \mathrm{pF}$ and $46 \mathrm{pA} / \mathrm{pF}$ in high- and low-CF neurons, respectively. The increase in the Kvl current and the decrease in the Kv3 current were reflected in the slow deactivation phase of the tail current in posthatch high-CF neurons (Rathouz and Trussell, 1998); the decay time constant in high-CF neurons was $2.7 \pm 0.2 \mathrm{~ms}(n=24)$ at E21 and $3.8 \pm 0.4 \mathrm{~ms}(n=18)$ at P3-P5 $(p=0.006)$, whereas, in low-CF neurons, it was $2.2 \pm 0.1 \mathrm{~ms}(n=$ $30)$ and $2.5 \pm 0.2 \mathrm{~ms}(n=19)$, respectively $(p=0.35)$. The composition and the size of the potassium current did not change further and persisted after P3-P5, indicating that the development of the potassium current reached a plateau within a few days after hatch.
The results indicated that the tonotopic differentiation of the Kv1 current progressed greatly after hatch, which was attributable to the increase in the Kv1 current in the high-CF neurons.

The $\mathrm{V}_{1 / 2}$ and slope factor of the Kv1 and Kv3 currents did not differ substantially among ages (E15-P11) in both high- and low-CF neurons and were similar to those in previous reports (E17-E20) (Rathouz and Trussell, 1998), suggesting that the characteristics of the channels did not change during development. Notably, however, the $\mathrm{V}_{1 / 2}$ was slightly depolarized $(2.7 \mathrm{mV})$ and the slope was steeper $(0.5 \mathrm{mV})$ for the Kv1 current in low-CF neurons (Fig. 2), which may suggest different modifications of the channels between the regions or may be related to the fact that the low-CF neurons possess extensive dendrites, which may be more difficult to effectively voltage clamp (Fig. 1D) (Jhaveri and Morest, 1982; Wang et al., 2017).

\section{Surface expression of Kv1.1 accounts for the increase in Kv1 current in high-CF neurons}

We next compared the expression levels of Kv1.1 and Kv3.1, which are the major subtypes of $\mathrm{Kv}$ channels in mature NM neurons, between tonotopic regions during development (Fig. 3). Kv1.1 signals were almost undetectable at E12 in both high- and low-CF neurons, while after E12 these signals increased in the soma as well as in the axon, particularly in high-CF neurons. Notably, however, the signals were mostly cytosolic during the embryonic period (Fig. 3A), which may suggest that Kv1.1 channels were accumulated in endoplasmic reticulum and/or Golgi apparatus, before hatch. When the signal intensity was measured in cytosolic regions in the soma (see Materials and Methods), the signals were $\sim 1.5$ times larger in high-CF neurons than low-CF neurons at E21 (Fig. 3E). This difference in Kv1.1 signals was slightly augmented in posthatch animals. More importantly, the signals clearly delineated the soma membrane after hatch, particularly in high-CF neurons. The Kv1.1 signals (Fig. 3C, red) were intermingled with a postsynaptic marker, PSD95 (green), indicating that Kv1.1 channels were distributed at the plasma membrane of postsynaptic NM neurons. Indeed, when the relative intensity was measured between membranous and cytosolic components (see Materials and Methods), it increased substantially after hatch in both neurons, and the extent of the increase was much larger in high-CF neurons (Fig. $3 F$ ). The results suggested that the membranous translocation of Kv1.1 was accelerated around hatch, particularly in higher-CF neurons, which would underlie the large increase in the Kv1 current in the neurons during this period.

The Kv3.1 signals were weak in cytoplasmic regions of both high- and low-CF neurons at E12 (Fig. 3B). This could be in part because the antibody recognized Kv3.1b (see Materials and Methods), whereas Kv3.1a, the other isoform of Kv3.1, is also expressed at this age (Parameshwaran-Iyer et al., 2003). The signals could also be 
A

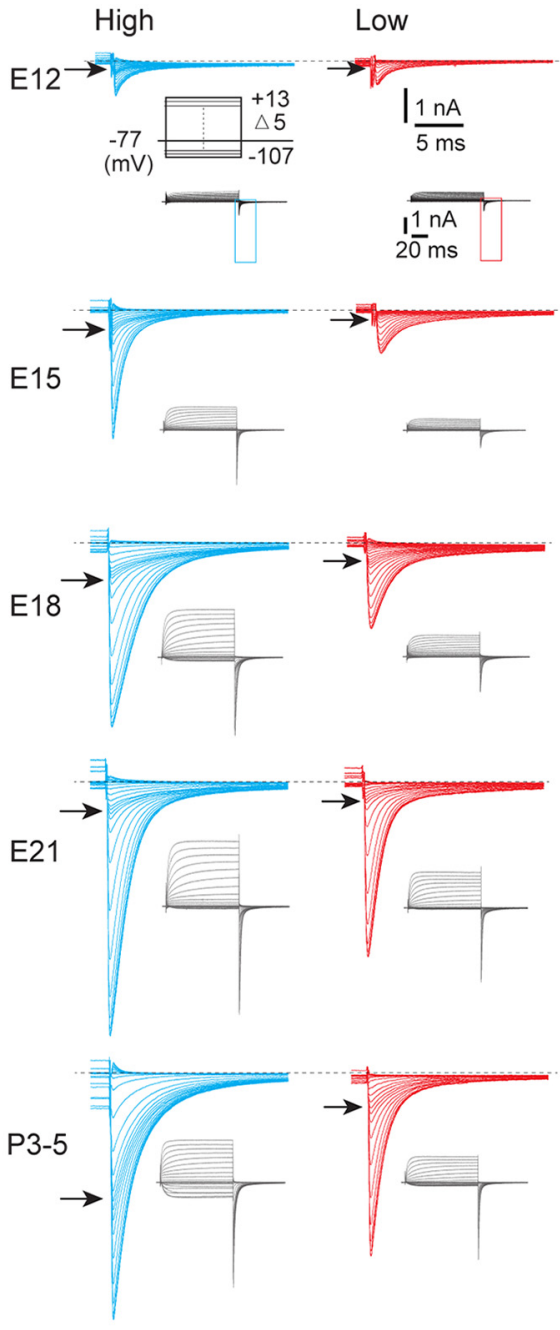

B
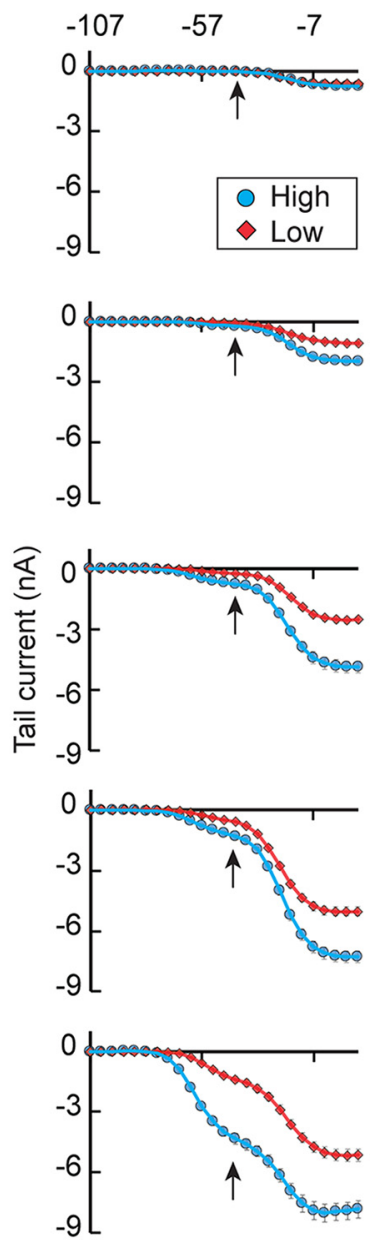

Membrane potential $(\mathrm{mV})$
C<smiles>[101InH]</smiles>
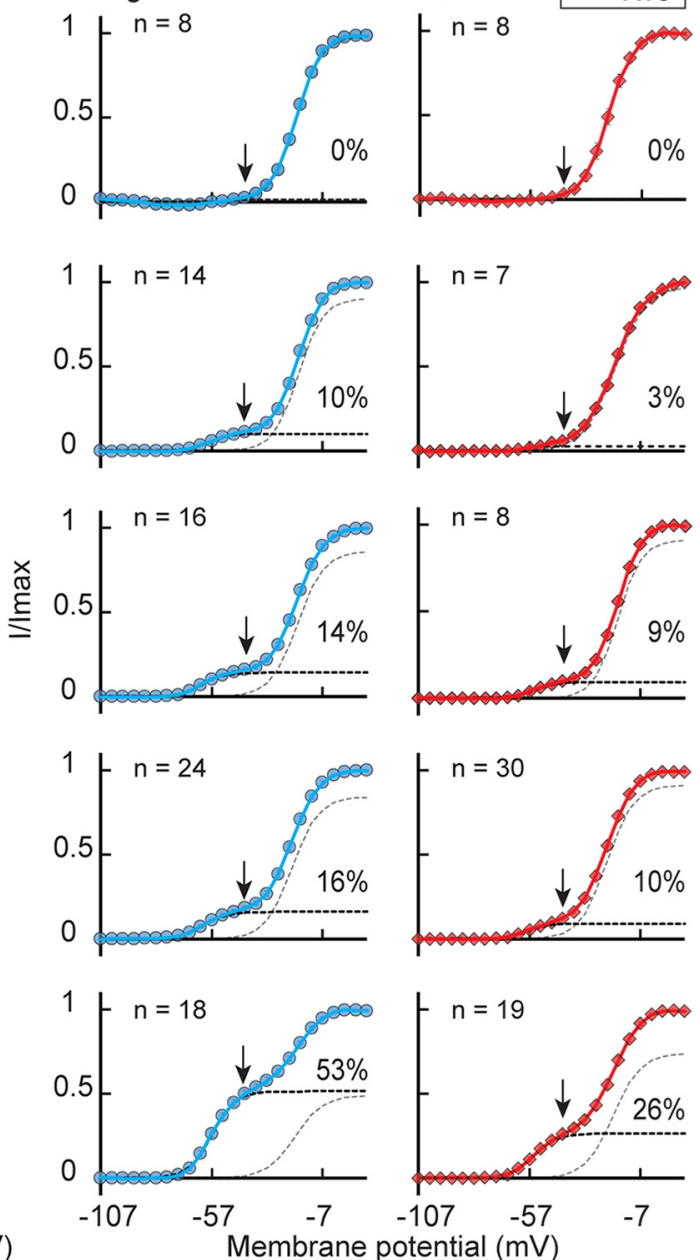

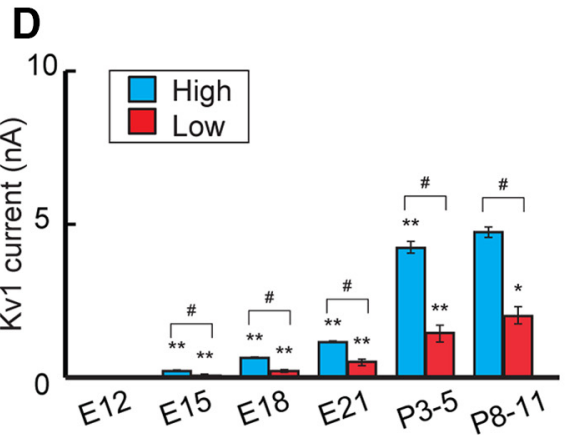

E

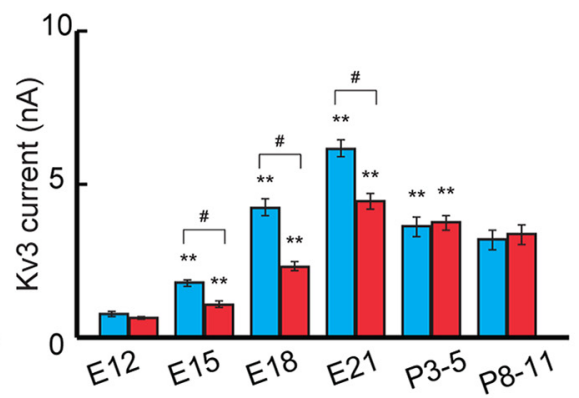

$\mathbf{F}$

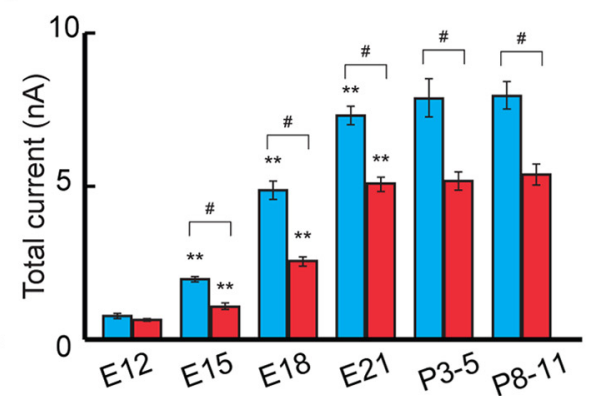

Figure 2. Development of potassium current. $A$, The potassium current in high-CF (left, blue) and low- $C F$ (right, red) neurons between E12 and P3-P5. The outward current appeared in response to voltage pulses ( $100 \mathrm{~ms}$ ) from -107 to $13 \mathrm{mV}$ with a $5 \mathrm{mV}$ step at $-77 \mathrm{mV}$ (inset), and the inward tail current was expanded. $\boldsymbol{B}$, Current-voltage relationship of the tail current in each population. C, Voltage dependence of activation curves from (B). The curves were fitted by a double Boltzmann equation, showing low-voltage-activating (Kv1, black) and high-voltage-activating (Kv3, gray) components (see Materials and Methods). The percentage of the Kv1 component is specified at right in each panel. Vertical and horizontal arrows indicate $-42 \mathrm{mV}(\boldsymbol{A}-\boldsymbol{C})$. $\boldsymbol{D}-\boldsymbol{F}, \mathrm{Maximum}$ amplitudes. Kv1 current $(\boldsymbol{D}), \mathrm{Kv} 3$ current $(\boldsymbol{E})$, and total current $(\boldsymbol{F}) . \mathrm{V}_{1 / 2}$ and slope factor did not change with age, whereas the Kv1 current differed slightly in the parameters between the tonotopic regions. For the Kv1 current, $V_{1 / 2}$ was $-58.0 \pm 0.3 \mathrm{mV}(n=50)$ and $-55.3 \pm 0.5 \mathrm{mV}(n=77)$ in high-and low-CF neurons, respectively $\left(p=1.3 \times 10^{-14}\right)$, whereas the slope factor was $4.7 \pm$ $0.1 \mathrm{mV}(n=50)$ and $4.2 \pm 0.1 \mathrm{mV}(n=77)$, respectively $(p=0.003)$. In contrast, for the Kv3 current, $\mathrm{V}_{1 / 2}$ was $-20.3 \pm 0.4 \mathrm{mV}(n=50)$ and $-20.3 \pm 0.4 \mathrm{mV}(n=77)$ in high- and low-CF neurons, respectively $(p=0.91)$, whereas the slope factor was $5.8 \pm 0.1 \mathrm{mV}(n=50)$ and $5.7 \pm 0.1 \mathrm{mV}(n=77)$, respectively $(p=0.21) .{ }^{*} p<0.05$ between tonotopic regions. ${ }^{*} p<0.05$ and ${ }^{* *} p<0.01$ compared with the neighboring younger group.

observed at the nucleus, which might be related to the fact that the endoplasmic reticulum is contiguous with the nuclear membrane. After E12, the Kv3.1 signals increased in cytosolic regions with some delays in the low-CF neurons and plateaued at a sim- ilar level around hatch in both neurons (Fig. 3G). Notably, Kv3.1 signals were also prominent at the plasma membrane in embryonic neurons (Fig. $3 B, D$ ), probably reflecting the large Kv3 current in embryos (Fig. 2). Nevertheless, the membranous signals 
A Kv1.1

High

E12

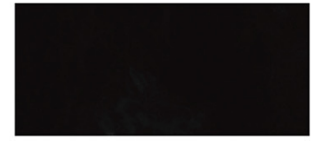

E15

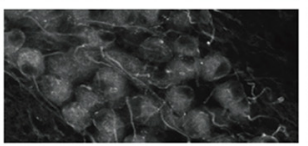

E18

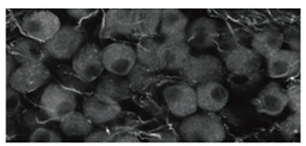

E21

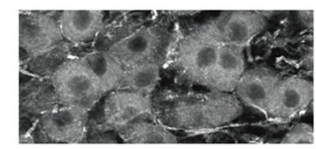

P3

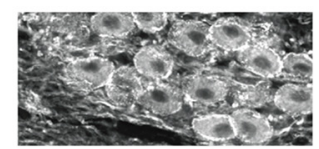

C Kv1.1

High

E21

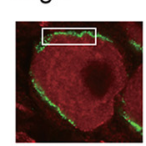

P3
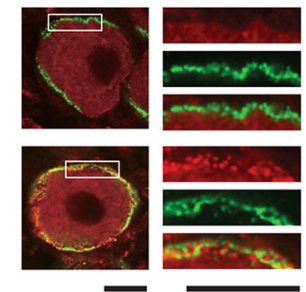

E Kv1.1

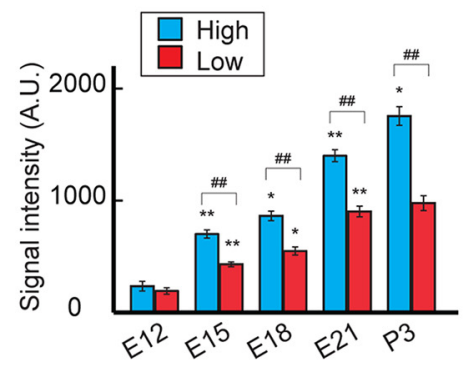

Low
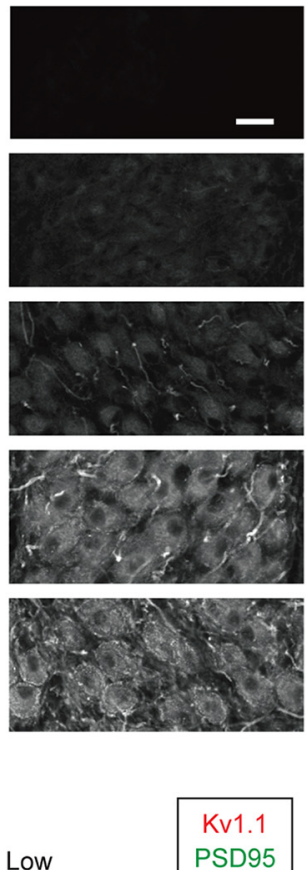

Low
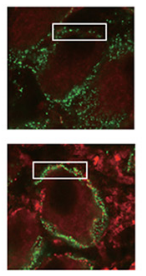

F
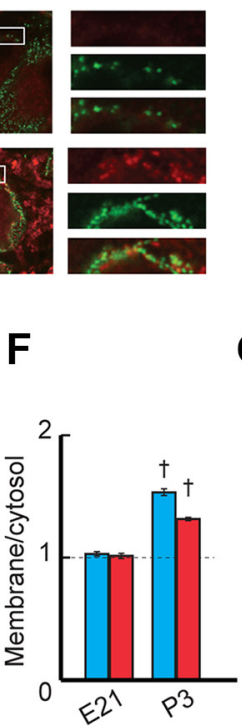

B Kv3.1

High
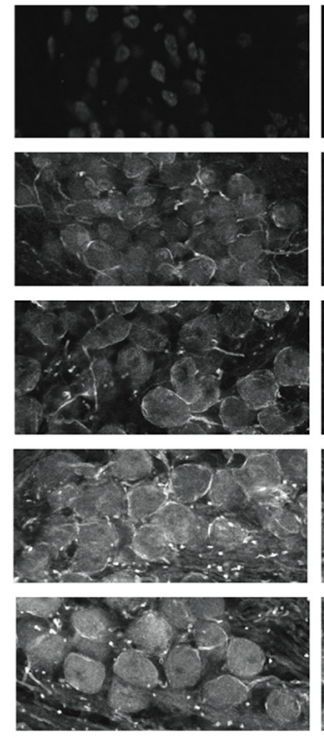

D kv3.1

\section{High}
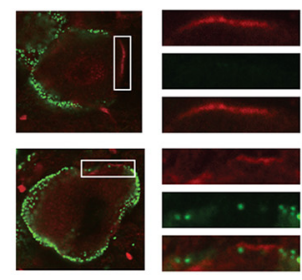

G Kv3.1

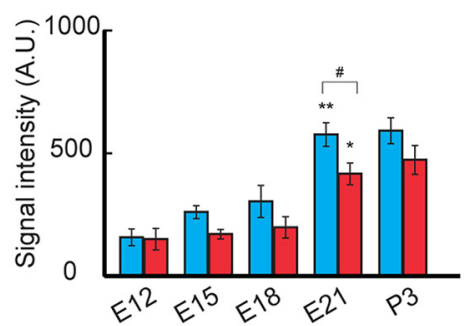

Low
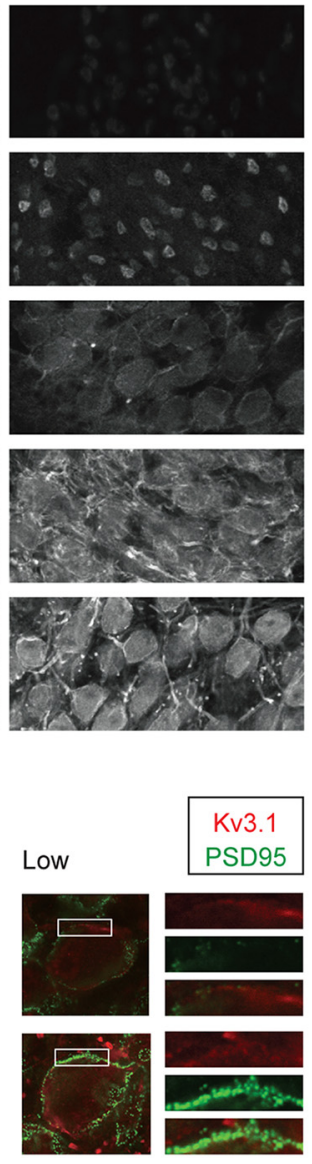

H

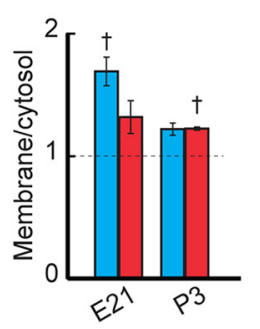

Figure 3. Development of Kv1.1 and Kv3.1 expression. $\boldsymbol{A}, \boldsymbol{B}$, Immunosignals of Kv1.1 ( $\boldsymbol{A})$ and Kv3.1 (B) in high-CF (left) and low-CF (right) regions of the NM between E12 and P3. Immunosignals increased after E12, whereas the increase was greatly augmented and membranous signals appeared for Kv1.1 after hatch particularly in the high-CF region. Fibrous signals could be observed after E15 for both Kv1.1 and Kv3.1, suggesting that axonal targeting of these channels progresses during the embryonic period (Kuba et al., 2015). C, D, Double immunostaining of Kv channels (red) and PSD95 (green) at E21 (top) and P3 (bottom). Right, Boxes are magnified. C, Kv1.1. D, Kv3.1. PSD95 signals surrounded the soma and intermingled with membranous Kv signals at P3, confirming that the Kv signals are on the plasma membrane of postsynaptic NM neurons. $\boldsymbol{E}, \boldsymbol{G}$, Signal intensity of Kv1.1 (E) and Kv3.1 (G) measured at cytosolic regions in the soma (see Materials and Methods). $\boldsymbol{F}, \boldsymbol{H}$, Ratio of membranous and cytosolic signal intensities of Kv1.1 (F) and Kv3.1 (H) at E21 and P3 (see Materials and Methods). Measurements were made from 3-7 animals in each group. Scale bars: $\boldsymbol{A}, \boldsymbol{B}, 20 \mu \mathrm{m} ; \boldsymbol{C}, \boldsymbol{D}, 10 \mu \mathrm{m} .{ }^{\#} p<0.05$ and ${ }^{\# \#} p<0.01$ between tonotopic regions. ${ }^{*} p<0.05$ and ${ }^{* *} p<0.01$ compared with the neighboring younger group. $† p<0.05$ between cytosolic and membranous signals.

decreased and no longer showed any tonotopic differences after hatch (Fig. $3 H$ ), which was consistent with the observations in the voltage-clamp experiments (Fig. 2).

Auditory inputs were required for the increase in the Kvl current after hatch

The sensitivity of the auditory nerve to sound increases in posthatch animals due to the improved conduction of airborne sound (Jones et al., 2006). This led to an idea that synaptic inputs to NM neurons increased around this period, which might trigger the increase of Kv1 current in the high-CF neurons. Thus, we attenuated auditory inputs around hatch to various levels by inducing sensorineural or conductive hearing loss (Fig. 4A; see Materials and Methods), and evaluated the effects on potassium currents at P3-P5 (Fig. 4B). The attenuation of auditory inputs reduced the tonotopic differentiation of the Kvl current in posthatch neurons (Fig. 4C,D). In high-CF neurons (left), removal of the cochlea suppressed the Kv1 current strongly (top), causing a slight 
A

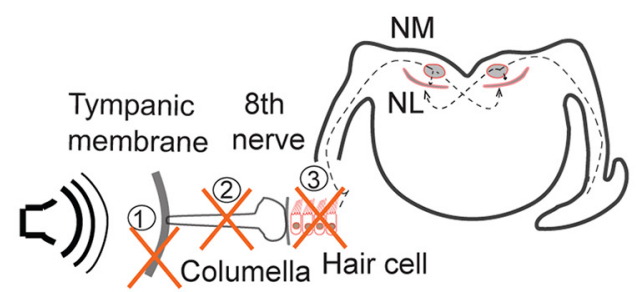

B

(1) Tymp removal

(2) Colum fixation

(3) Coch removal

\section{G}

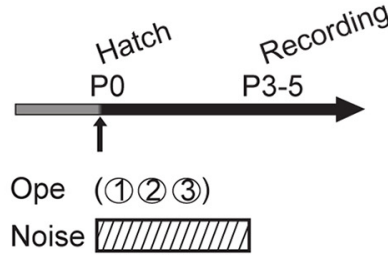

Noise WIIIIIIIII C High Low

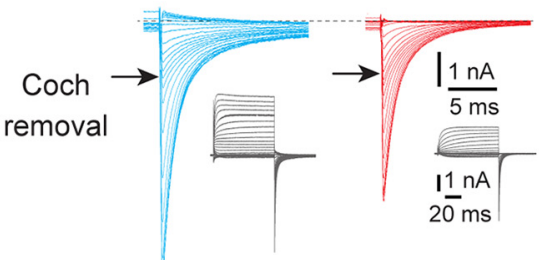

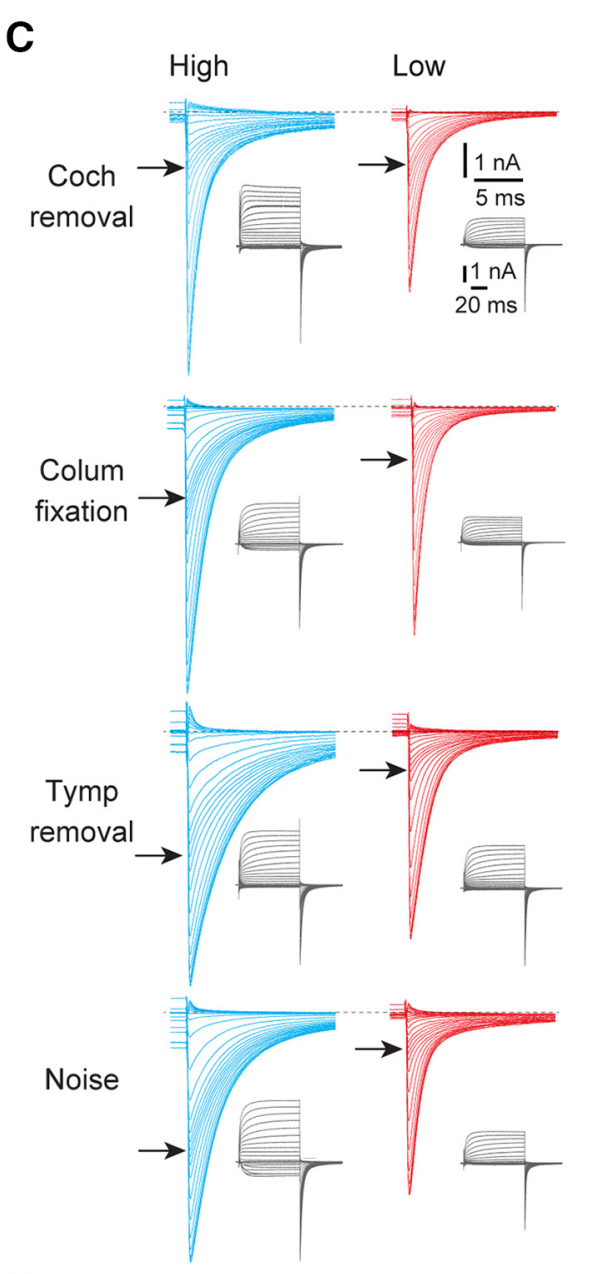

E

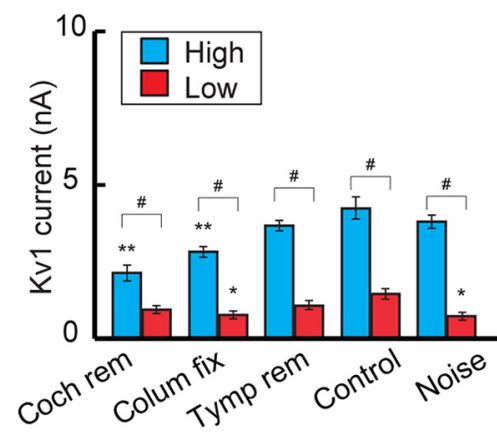

$\mathbf{F}$
D
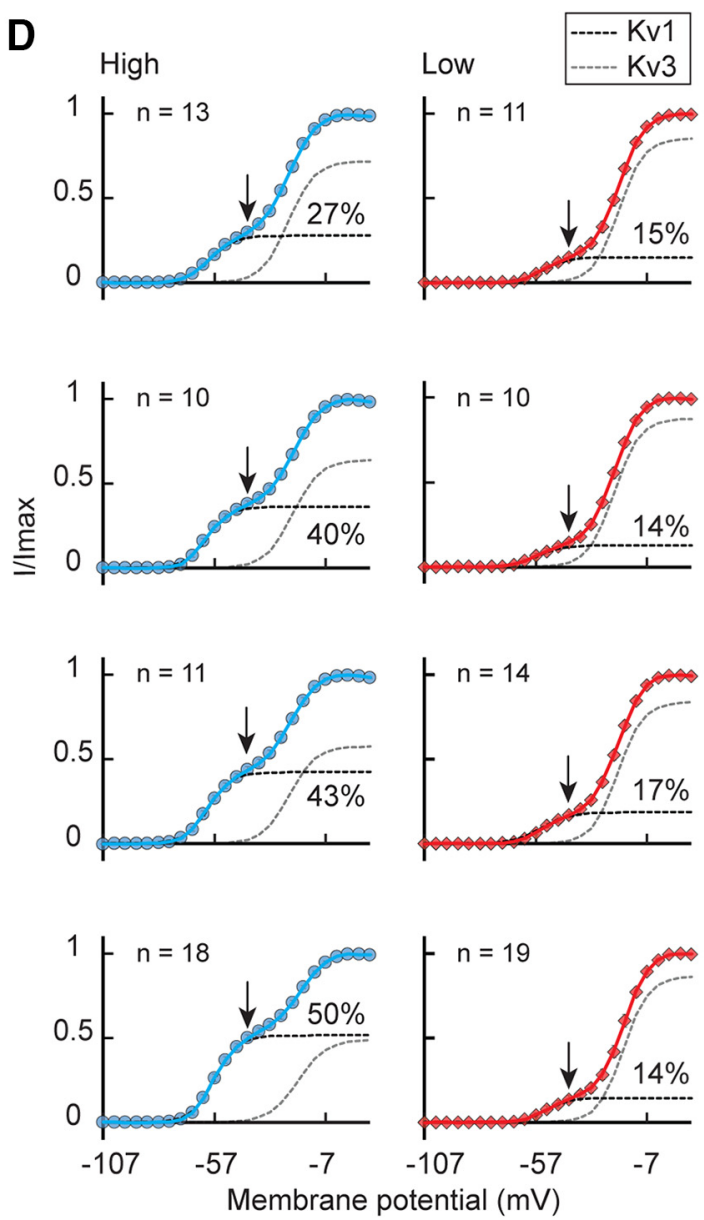

Membrane potential (mV)
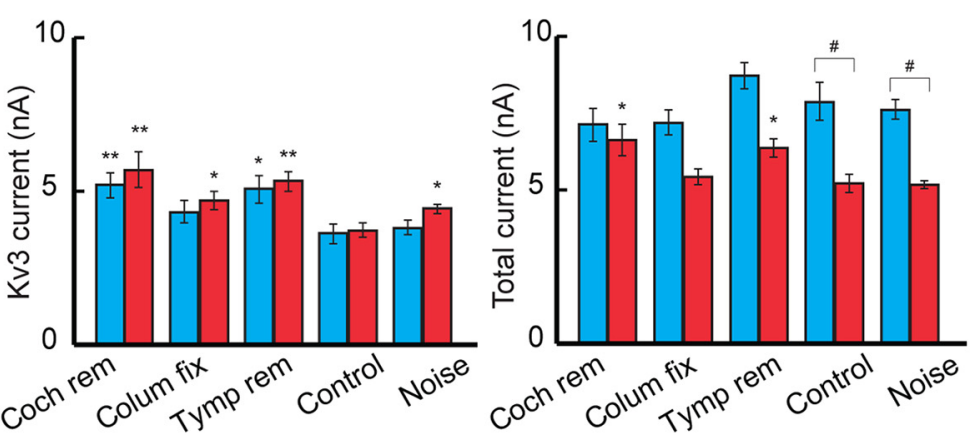

Figure 4. Effects of auditory inputs on the potassium current after hatch. $\boldsymbol{A}, \boldsymbol{B}$, Auditory inputs were attenuated or elevated between P0 and P3-P5 by tympanic membrane removal, columella fixation, cochlea removal at $\mathrm{PO}$, or by exposing animals to noise during the indicated period. C, Potassium current in high-CF (left, blue) and low-CF (right, red) neurons at P3-P5. Top, Cochlea removal. Upper middle, Columella fixation. Lower middle, Tympanic membrane removal. Bottom, Noise exposure. $\boldsymbol{D}$, Voltage dependence of activation curves. The curves were fitted by a double Boltzmann equation, showing low-voltage-activating (Kv1, black) and high-voltage-activating (Kv3, gray) components (see Materials and Methods). Percentage of the Kv1 component is specified at right in each panel. Vertical and horizontal arrows indicate $-42 \mathrm{mV}(\boldsymbol{C}, \boldsymbol{D}) . \boldsymbol{E}-\boldsymbol{G}$, Maximum amplitudes. Kv1 current $(\boldsymbol{E})$, Kv3 current $(\boldsymbol{F})$, and total current $(\mathbf{G})$. Control is a replot of Figure 2 (P3-P5). $V_{1 / 2}$ and slope factor of Kv1 and Kv3 currents did not change after the manipulations $(p>0.05$, ANOVA). "\# $p<0.05$ between tonotopic regions. ${ }^{*} p<0.05$ and ${ }^{* *} p<0.01$ compared with control. 
A $\mathrm{Kv1} 1 \mathrm{1}$

P3 High
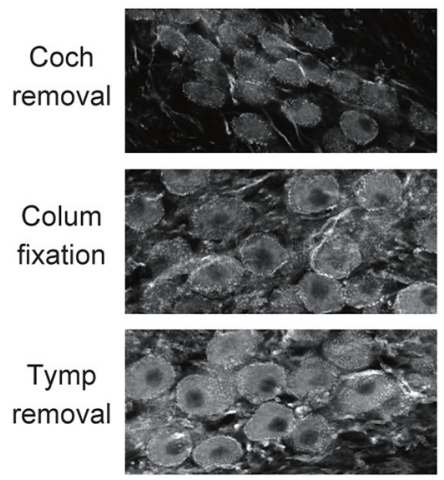

Control

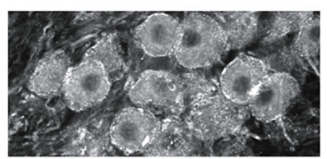

Noise
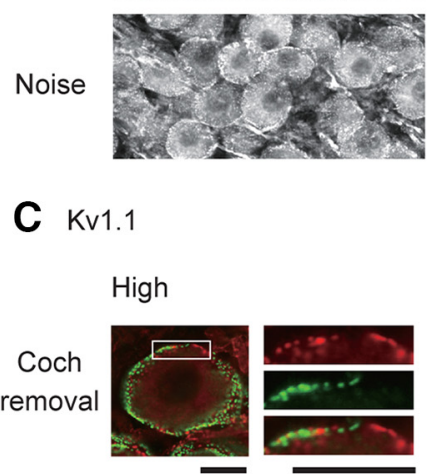

E Kv1.1

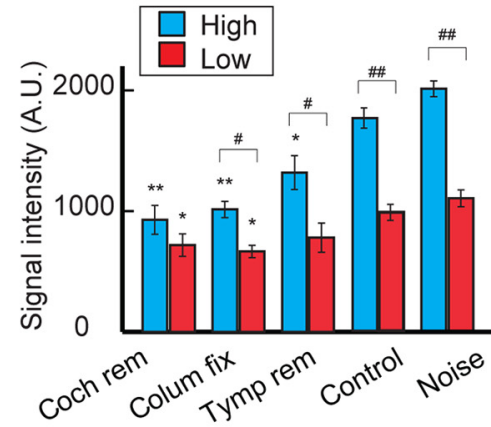

Low
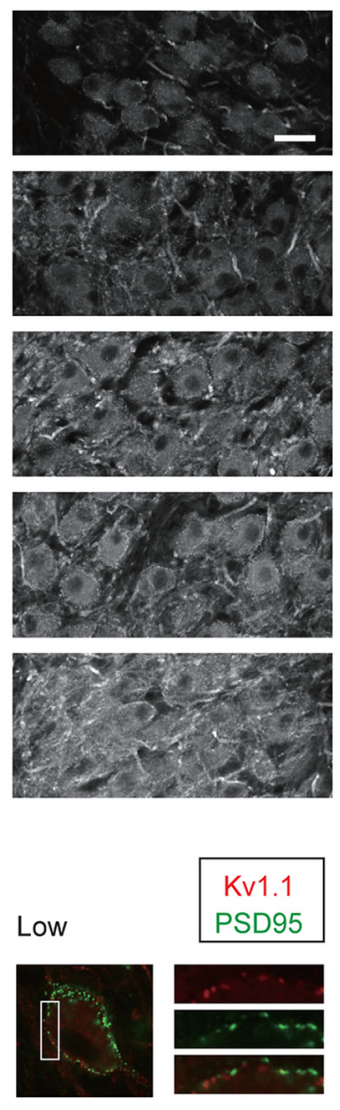

F
B Kv3.1

High
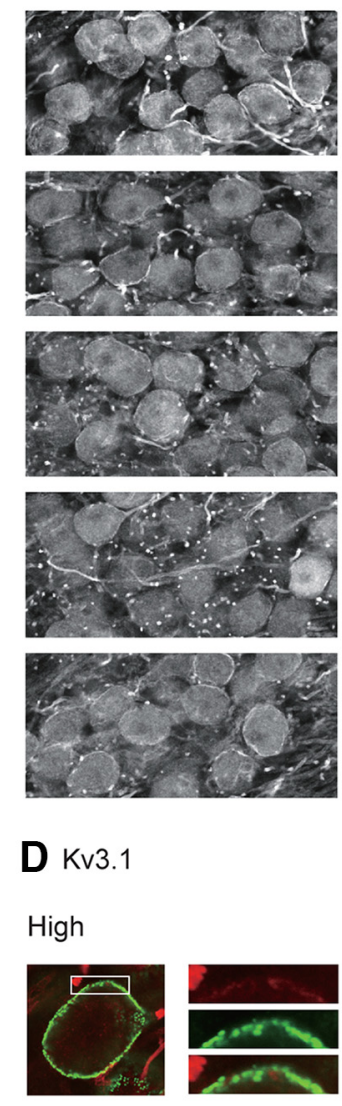

G Kv3.1
Low
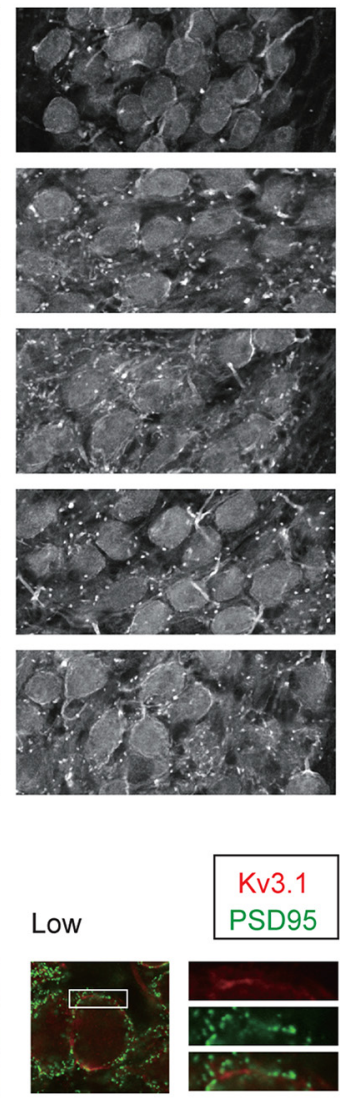

H
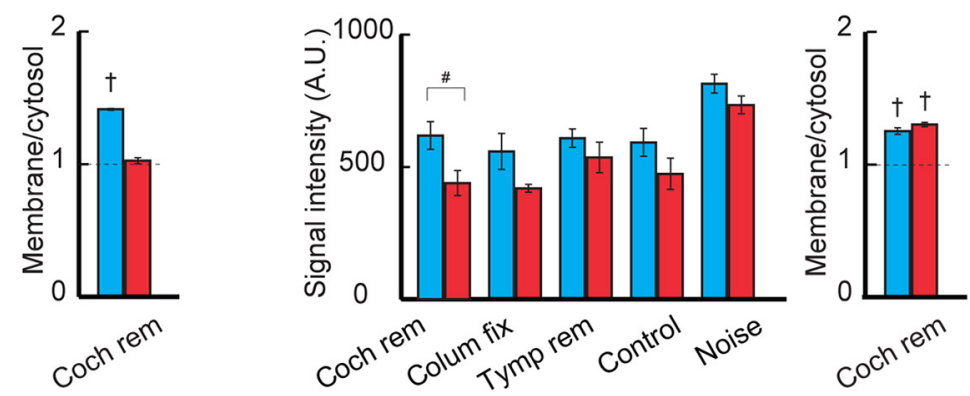

Figure 5. Effects of auditory inputs on Kv1.1 and Kv3.1 expression after hatch. $\boldsymbol{A}, \boldsymbol{B}, \mathrm{Immunosignals} \mathrm{of} \mathrm{Kv1.1} \mathrm{(A)} \mathrm{and} \mathrm{Kv3.1} \mathrm{(B)} \mathrm{at} \mathrm{P3} \mathrm{after} \mathrm{attenuation} \mathrm{or} \mathrm{elevation} \mathrm{of} \mathrm{auditory} \mathrm{inputs} \mathrm{after} \mathrm{hatch.}$ Top, Cochlea removal. Upper middle, Columella fixation. Middle, Tympanic membrane removal. Lower middle, Control. Bottom, Noise exposure. C, D, Double immunostaining of Kv channels (red) and PSD95 (green) at P3 after cochlea removal. Right, Boxes are magnified. Kv1.1 (C) and Kv3.1 (D). PSD95 signals were still intermingled with membranous Kv signals after cochlea removal. $\boldsymbol{E}, \boldsymbol{G}$, Signal intensity of Kv1.1 (E) and Kv3.1 (G) measured at cytosolic regions in the soma. $\boldsymbol{F}, \boldsymbol{H}$, Ratio of membranous and cytosolic signal intensities of Kv1.1 (F) and Kv3.1 (H) after cochlea removal. Measurements were made from 3 to 5 animals in each group. Areas as well as intensities of membranous Kv1.1 signals decreased after cochlea removal in both high- and low-CF neurons. Scale bars: $A, B, 20 \mu \mathrm{m} ; \boldsymbol{C}, \boldsymbol{D}, 10 \mu \mathrm{m} .{ }^{\#} p<0.05$ and ${ }^{\# \#} p<0.01$ between tonotopic regions. ${ }^{*} p<0.05$ and ${ }^{* *} p<0.01$ compared with control. $\dagger p<0.05$ between membranous and cytosolic signals.

reduction in total potassium current (Fig. 4E, G); the Kv1 current decreased by $\sim 50 \%$ after cochlea removal $(2.1 \mathrm{nA})$ compared with that in control $(4.3 \mathrm{nA})$. Consistently, cochlea removal shortened the decay time constant of the tail current by $29 \%$ in high-CF neurons $(2.7 \pm 0.2 \mathrm{~ms}, n=13, p=0.015$ compared with control). The Kv1 current was also suppressed but to a smaller extent in the neurons after fixation of middle ear bone (columella) (upper middle) or removal of tympanic membrane (lower middle) (see Materials and Methods), which preserves hair cells but attenuates sound by $35-60 \mathrm{~dB}$ and $30-35 \mathrm{~dB}$, respectively
(Table 1). Thus, attenuation of auditory inputs suppressed the Kv1 current in a level-dependent manner in the high-CF neurons, indicating that the increase of $\mathrm{Kvl}$ current in the neurons was triggered by auditory inputs around the hatching period. We also exposed the animals to white noise (see Materials and Methods) after hatch (bottom), but this exposure did not affect the $\mathrm{Kv} 1$ current, which may suggest that the increase of Kv1 current is already maximal at normal sound levels (60 dB). In low-CF neurons (right), in contrast, a decrease or an increase in auditory inputs had little effect on the Kv1 current, suggesting that the 
A

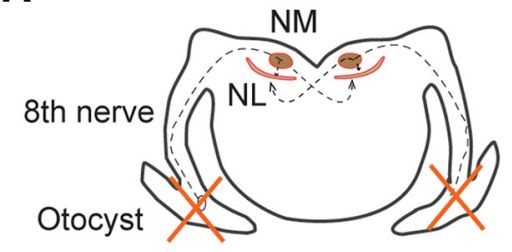

C

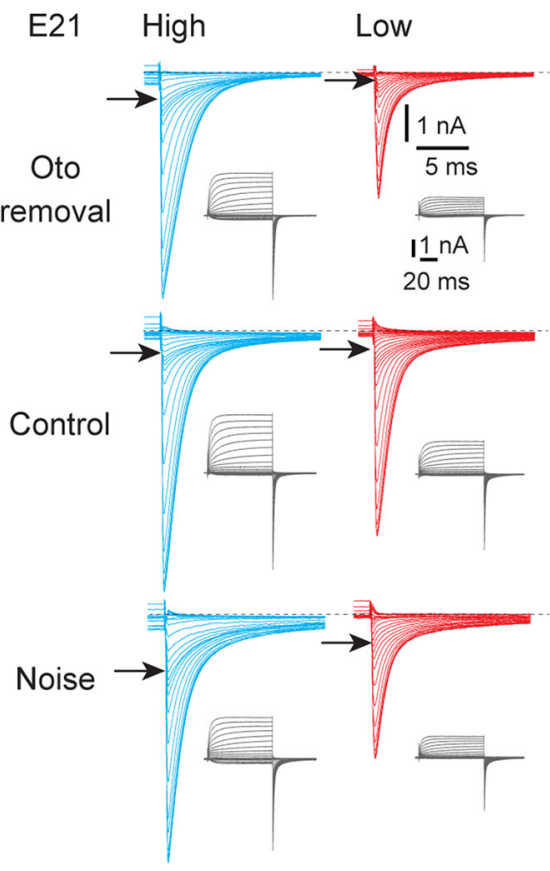

B

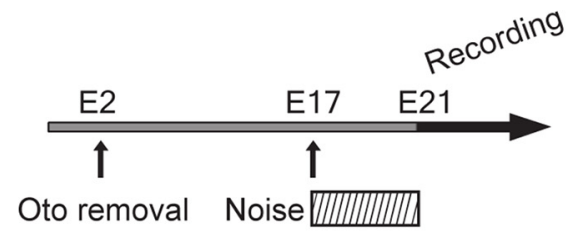

D
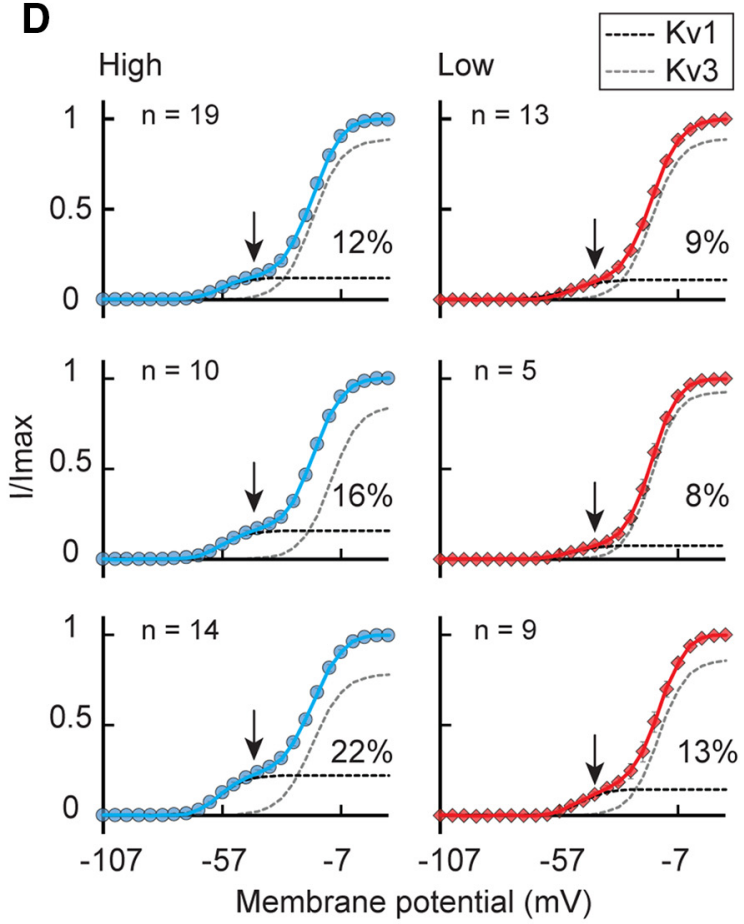

E

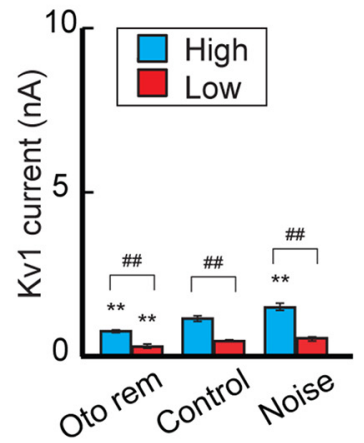

$\mathbf{F}$

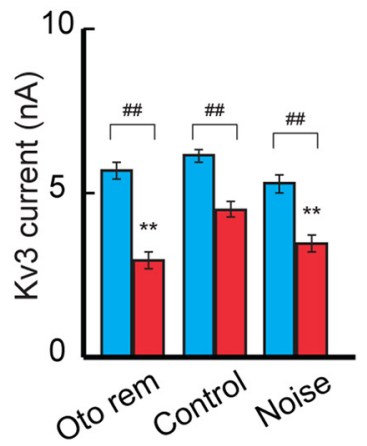

G

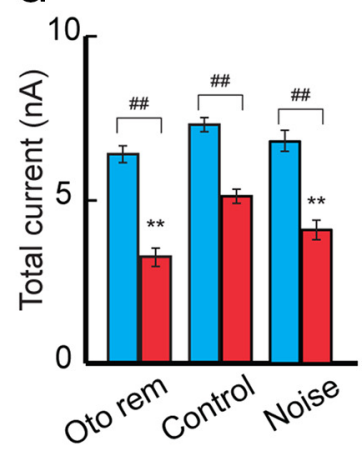

Figure 6. Effects of auditory inputs on the potassium current in embryos. $A, B$, Auditory inputs were attenuated or elevated in embryos by bilateral otocyst removal at E2 or by exposing eggs to noise between E17-E21. C, Potassium current in high-CF (left, blue) and low-CF (right, red) neurons at E21. Top, Otocyst removal. Middle, Control. Bottom, Noise exposure. D, Voltage dependence of activation curves. The curves were fitted by a double Boltzmann equation, showing low-voltage-activating (Kv1, black) and high-voltage-activating (Kv3, gray) components (see Materials and Methods). Percentage of the Kv1 component is specified at right in each panel. Vertical and horizontal arrows indicate $-42 \mathrm{mV}(\boldsymbol{C}, \boldsymbol{D})$. $\boldsymbol{E}-\boldsymbol{G}$, Maximum amplitudes. Kv1 current $(\boldsymbol{E})$, Kv3 current $(\boldsymbol{F})$, and total current $(\boldsymbol{G})$. The $V_{1 / 2}$ and slope factor of the Kv1 and Kv3 currents did not change after the manipulations $\left(p>0.05\right.$, ANOVA). ${ }^{\# \#} p<0.01$ between tonotopic regions. ${ }^{* *} p<0.01$ compared with control.

input-dependent mechanism to accelerate Kv1.1 expression is less active in the low-CF neurons. Consistent with this idea, the immunosignals of Kv1.1 decreased in a level-dependent manner, and the extent of this reduction was more prominent in high-CF neurons (Fig. 5A,E). In addition, Kv1.1 signals at the plasma membrane were decreased after cochlea removal particularly in the high-CF neurons; the ratio of membranous and cytosolic components was $1.41 \pm 0.01(n=3)$ after cochlea removal and $1.53 \pm 0.03(n=3)$ in control chicks $(p=0.006)$ (Fig. $5 C, F$; see also Fig. $3 F$ ). The results indicated that the processes of synthesis and translocation of Kv1.1 proteins are dependent on auditory inputs and accelerated around hatch in high-CF neurons.

The Kv3 current was slightly increased $3 \mathrm{~d}$ after cochlea removal with little difference between the tonotopic regions (Fig. $4 D, F)$. However, the effects were rather variable in the other manipulations of auditory inputs. In addition, the manipulations of inputs did not affect the Kv3.1 signals in membranous or cytosolic regions in either the high- or low-CF neurons (Fig. $5 B, D, G, H)$, suggesting that auditory inputs have small effects on Kv3.1 expression in the NM, consistent with the observations 
A Kv1.1

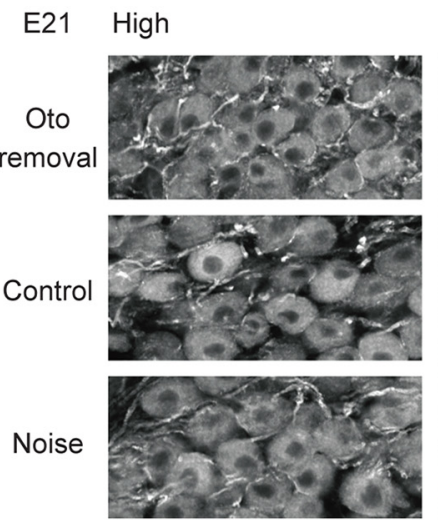

C Kv1.1

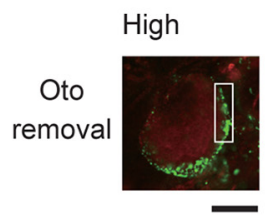

E Kv1.1

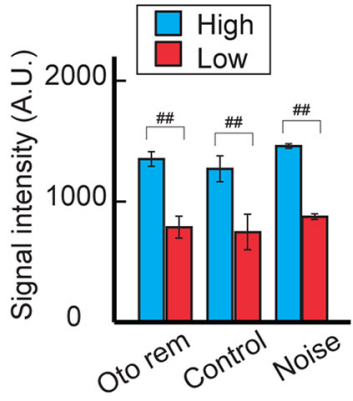

Low
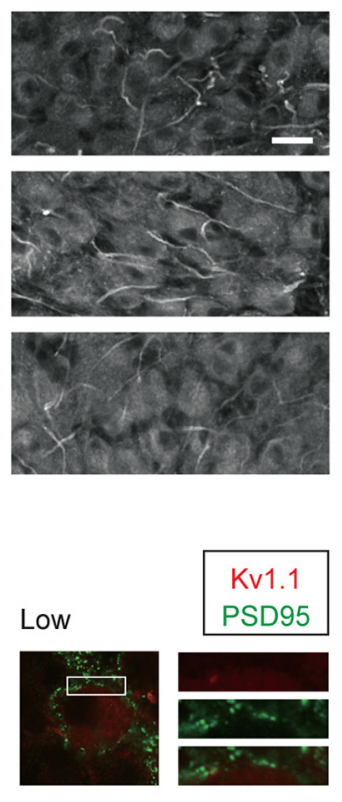

F

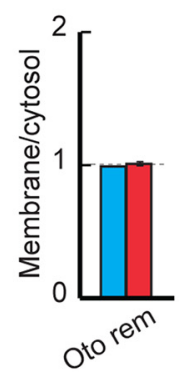

B Kv3.1

High
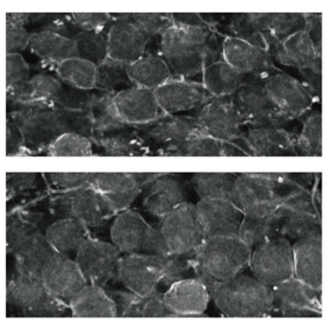

Low
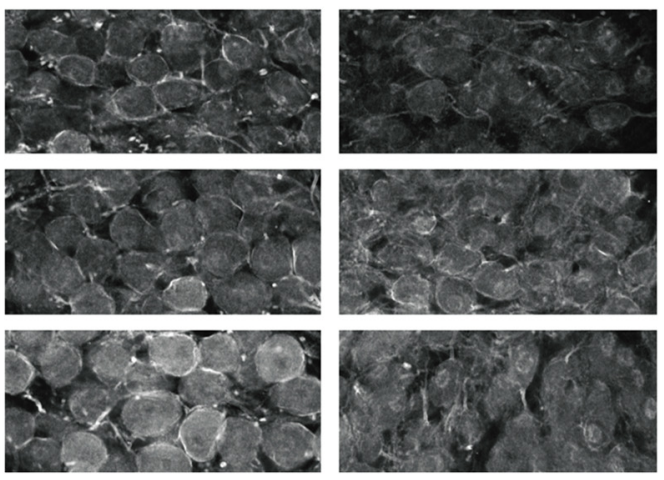

D Kv3.1
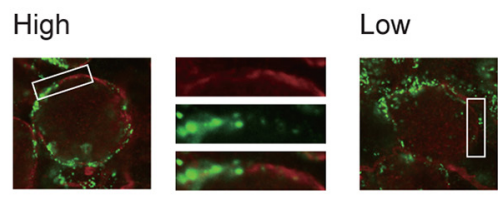

Kv3.1

PSD95

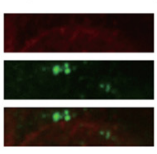

H

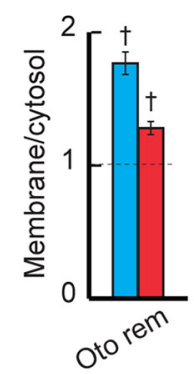

Figure 7. Effects of auditory inputs on Kv1.1 and Kv3.1 expression in embryos. $\boldsymbol{A}, \boldsymbol{B}$, Immunosignals of Kv1.1 ( $\boldsymbol{A})$ and Kv3.1 ( $\boldsymbol{B})$ at E21 after attenuation or elevation of auditory inputs in embryos. Top, Otocyst removal. Middle, Control. Bottom, Noise exposure. C, D, Double immunostaining of Kv channels (red) and PSD95 (green) at E21 after otocyst removal. Right, Boxes are magnified. Kv1.1 $(\boldsymbol{C})$ and Kv3.1 (D). Kv signals did not change much after otocyst removal. $\boldsymbol{E}, \mathbf{G}$, Signal intensity of Kv1.1 (E) and Kv3.1 (G) measured at cytosolic regions in the soma. $\boldsymbol{F}, \boldsymbol{H}$, Ratio of membranous and cytosolic signal intensities of Kv1.1 $(\boldsymbol{F})$ and $\mathrm{Kv} 3.1(\boldsymbol{H})$ at E21 after otocyst removal. Measurements were made from 3 animals in each group. Scale bars: $\boldsymbol{A}, \boldsymbol{B}, 20 \mu \mathrm{m} ; \boldsymbol{C}, \boldsymbol{D}, 10 \mu \mathrm{m}$. ${ }^{\#} p<0.01$ between tonotopic regions. $t p<0.05$ between membranous and cytosolic signals.

in older animals (Kuba et al., 2015; for transient effects within $24 \mathrm{~h}$, see Lu et al., 2004).

Auditory inputs had smaller effects on the development of the Kv1 current before hatch

Although the extent was small, the Kv1 and Kv3 currents were tonotopically differentiated before hatch (Fig. 2). We therefore examined the effects of auditory inputs on differentiation of the potassium currents in embryos (Fig. 6). We either eliminated or elevated auditory inputs during the embryonic period by removing bilateral otocysts at E2 or exposing animals to noise for $4 \mathrm{~d}$ until E21 (Fig. 6A,B). Removal of otocysts decreased Kv1 current, whereas noise exposure increased the current in high-CF neurons (Fig. 6C). However, the absolute magnitude of the change was small $(0.4 \mathrm{nA})$, which contrasted with the large decrease of Kv1 current after cochlea removal in posthatch neurons (2.1 nA) (Fig. 6D,E,G; see also Fig. 4). The relative magnitude change of the current was also smaller in embryos (30\% of control) compared with hatchlings ( $50 \%$ of control). Moreover, the tonotopic difference in the Kv1 current largely remained after manipulation of sensory input. These results indicated that the contributions of auditory inputs to the differentiation of Kv1 current are small during the embryonic period. This view is supported by the immunohistochemical observations that the manipulations of auditory inputs had little effect on the cytosolic as well as the membranous signals of Kv1.1 at the soma (Fig. $7 A, C, E, F$; see also Fig. $3 F$ ).

The elimination or elevation of auditory inputs affected neither the development of the Kv3 current (Fig. $6 C, D, F$ ) nor the membranous Kv3.1 signals (Fig. $7 B, D, G, H$ ) in high-CF neurons. In addition, the tonotopic differences in the Kv3 current remained regardless of the manipulations. All of these results indicated that the differentiation of $\mathrm{Kv}$ channels are less dependent on auditory experiences during the embryonic period.

\section{Discussion}

Development of Kv currents in NM neurons

The development of postsynaptic membrane properties of high-CF NM neurons was previously examined in embryonic chickens, showing a gradual increase in potassium conductance 
between E10 and E21, with some delay in the low-voltage-activating component (Hong et al., 2016). These observations were consistent with the present findings; the Kv3 current could be observed at E12, whereas the Kv1 current first appeared at E15 in the neurons (Fig. 2). However, the increase in Kv1 current differed depending on the CF, causing a slight tonotopic difference in the current during the embryonic period. In posthatch animals, on the other hand, the increase of Kv1 current was augmented particularly in higher-CF neurons, making this current far larger in these neurons. More importantly, the increase was strongly dependent on the level of the auditory input, suggesting that auditory experience is critical in the tonotopic differentiation of the Kvl current. The Kv3 current also increased during the embryonic period to a larger extent in higher-CF neurons, whereas it declined and became similar in size across tonotopic regions after hatch. This process progressed in the absence of auditory inputs, suggesting that it is independent of auditory experience.

\section{Roles of auditory inputs in the tonotopic differentiation of \\ Kv1.1 channels}

In NM, synaptic responses can be recorded as early as E11 (Gao and Lu, 2008), and auditory evoked responses appear at E12, but the threshold is still high and hearing is not efficient until E20, due in part to the fluid in the ears (Saunders et al., 1973; Jones et al., 2006). With a clearance of the fluid, the auditory threshold decreases greatly and reaches the mature level within a few days after hatch. These observations may suggest that the expression of Kv1.1 became more efficient in high-CF neurons around hatch simply due to the increase of input in the neurons at this period. However, this is an unlikely possibility for the following reasons. First, the input dependence was more prominent in high-CF neurons (Figs. 4, 5), even though the auditory threshold is $>20-30$ $\mathrm{dB}$ higher for high-frequency sound than for low-frequency sound (Table 1; Fig. 8). Second, exposing embryos to noise could not reproduce the increase in the current observed in posthatch neurons (Figs. 6, 7), suggesting that the increase of auditory inputs cannot solely explain the augmentation of Kv1.1 expression in the high-CF neurons after hatch, although a possibility remains that the noise might not be strong enough to activate embryonic neurons substantially (see Materials and Methods). Thus, another possible explanation could be that a mechanism coupling neuronal activity with Kv1.1 expression is strengthened around hatch, enabling a more efficient Kv1.1 expression in posthatch high-CF neurons (Fig. 8). This further indicates that the capacity of neurons to drive Kv1.1 expression via auditory input is determined in a cell-specific manner in NM, being higher in high-CF neurons, which mediates the increase of Kv1.1 in the neurons after hatch.
Low

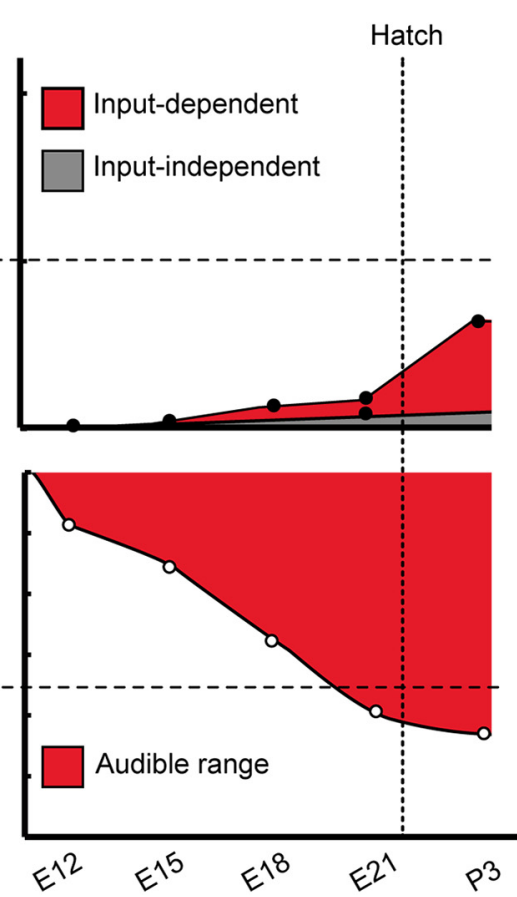

Figure 8. Mechanism of tonotopic differentiation of Kv1.1 expression. The rate of Kv1-current increase (top) was compared (black circles) from values in Figure 2. Input-independent increase was from a linear extrapolation to the value As the auditory threshold is higher for high-frequency sound, the capacity to drive Kv1.1 expression via auditory inputs would be strengthened in the high-CF neurons in hatchlings. On the other hand, the capacity could be low in both neurons in embryos because noise exposure had small effects on Kv1 current and Kv1.1 signals before hatch (Figs. 6, 7).

The auditory nerve is activated by spontaneous as well as sound-driven transmitter release from hair cells in the cochlea. Indeed, the spontaneous field potential is recorded at the NM as a rhythmic burst pattern around E14-E18 and as a continuous burst pattern before hatch (Lippe, 1994). Importantly, the rate of bursting correlates with CF in embryonic chickens (Lippe, 1995; Johnson et al., 2011). In addition, spontaneous input is known to refine auditory brainstem circuits in mammals (Kandler et al., 2009; Wang and Bergles, 2015). However, the contribution of spontaneous input to the tonotopic differences in $\mathrm{Kv}$ currents may be small in the embryonic NM because the differences remained after removal of otocysts, which is known to abolish both spontaneous and sound-driven inputs. Nevertheless, it is still possible that spontaneous input from other sources and/or of NM neurons themselves might arise and drive the embryonic differentiation after otocyst removal. Notably, the auditory nerve does not differ in the spontaneous discharge rate among tonotopic regions after hatch (Manley et al., 1991), supporting the idea that the neuronal capacity to drive ion channel expression via afferent input rather than the level of input would be responsible for the tonotopic differentiation of Kv1.1 expression in the posthatch NM.

\section{Molecular mechanism of the tonotopic differentiation of Kv1.1 channels}

Surface expression of Kv1.1 increased in an auditory input-dependent manner in posthatch NM neurons and to a larger extent in 
high-CF neurons. There are several channel domains that regulate the membrane trafficking of Kvl channels (Vacher and Trimmer, 2012; Ovsepian et al., 2016). These include the ER-retention domain at the external pore region (Manganas et al., 2001), the anterograde-trafficking domain at the C-terminal region ( $\mathrm{Li}$ et al., 2000), and the Kv $\beta 2$-subunit-binding domain at the T1 region (Shi et al., 1996; Watanabe et al., 2014). Among them, the ER-retention domain dominates over the other domains in Kv1.1 and may play a primary role in the regulation of its expression in posthatch NM neurons. The ER-retention domain corresponds to the dendrotoxin-binding motif of Kv1 channels, and an endogenous dendrotoxin-like protein may bind to this motif and contribute to ER retention (Vacher et al., 2007). Recent studies have proposed that matrix metalloprotease 23 (MMP23), which is a Type II membrane protein in ER/nuclear membranes, is a candidate for this role (Rangaraju et al., 2010) as it binds to the motif but is released from the ER membrane via a $\mathrm{Ca}^{2+}$ dependent cleavage by an endoprotease, furin (Salvas et al., 2005; Galea et al., 2014). Thus, one possible mechanism could be that the increase in auditory inputs elevates the $\mathrm{Ca}^{2+}$ level in the ER in posthatch NM neurons, which induces cleavage of MMP23 and promotes the membrane trafficking of Kvl.1 in the neurons.

The expression of Kv1.1 during the embryonic period was less dependent on auditory inputs. Notably, NM neurons experience downregulation of trkB, a BDNF receptor, after E8, and suppressing this downregulation prevents the development of the Kv1 current during the embryonic period (Schecterson et al., 2012), suggesting that the input-independent mechanism may involve this downregulation of trkB in embryonic neurons.

\section{Functional implication of input-dependent differentiation of Kv1.1 channels}

The Kv3 current is dominant in both high- and low-CF NM neurons during the embryonic period, while the Kv1 current increases and becomes dominant after hatch, particularly in high-CF neurons. Dominance of the Kv3 current would be beneficial for embryonic NM neurons because it promotes spike generation via acceleration of repolarization (Brew and Forsythe, 1995), which may compensate for the low level of inputs and help the neurons maintain a substantial level of firing in the embryonic neurons (Hong et al., 2016). What is the functional implication of increasing the Kv1 current around hatch in the high-CF neurons? As the increase progresses in parallel with the maturation of synapses, we can expect that this change is necessary for the neurons to adapt electrically to the increase in synaptic inputs during maturation. Indeed, the auditory threshold decreases (Saunders et al., 1973), and the synaptic strength at the NM continues to be augmented after hatch through a decrease in synaptic depression and increases in the readily releasable pool size and vesicle content (Brenowitz and Trussell, 2001). This implies that the frequency and the size of inputs to individual NM neurons increase in posthatch animals. Mature high-CF NM neurons receive strong synaptic inputs and require a large Kv1 current to suppress aberrant spike generation during the large synaptic depolarization (Brew and Forsythe, 1995). Therefore, the increase in Kv1 current may be critical for the neurons to counterbalance the increase in synaptic inputs and accomplish precise temporal coding. In contrast, low-CF neurons have multiple converging inputs that generate spikes, and a large Kv1 current is rather disadvantageous for the neurons to generate a spike in response to the slowly rising synaptic depolarization (Kuba and Ohmori, 2009). Thus, it is reasonable that the mechanism to increase the Kvl current is more active in high-CF neurons and dependent on auditory inputs, which enables a fine adjustment of the Kv1 current according to the level of inputs. Although small and slow, the Kv7 current is known to negatively correlate with the Kv1 current at the axon initial segment in mature animals (Kuba et al., 2015) and would further contribute to the regulation of the excitability of the neurons.

Tonotopic differentiation of the Kv1 current is observed in various nuclei along the auditory time-coding pathway (BarnesDavies et al., 2004; Kuba et al., 2005; Leao et al., 2006). Therefore, the input-dependent regulation of Kv1-channel expression may be an efficient strategy of the auditory system to ensure precise and reliable time coding across frequencies under variable environments. Moreover, the present results highlight the importance of the neuronal capacity for sound to drive ion channel expression and the level of auditory experience in shaping the frequency-specific tuning of the auditory system during development.

\section{References}

Barnes-Davies M, Barker MC, Osmani F, Forsythe ID (2004) Kvl currents mediate a gradient of principal neuron excitability across the tonotopic axis in the rat lateral superior olive. Eur J Neurosci 19:325-333. CrossRef Medline

Brenowitz S, Trussell LO (2001) Minimizing synaptic depression by control of release probability. J Neurosci 21:1857-1867. Medline

Brew HM, Forsythe ID (1995) Two voltage-dependent $\mathrm{K}^{+}$conductances with complementary functions in postsynaptic integration at a central auditory synapse. J Neurosci 15:8011-8022. Medline

Cohen YE, Saunders JC (1994) The effect of acoustic overexposure on the tonotopic organization of the nucleus magnocellularis. Hear Res 81: 11-21. CrossRef Medline

Fukui I, Ohmori H (2004) Tonotopic gradients of membrane and synaptic properties for neurons of the chicken nucleus magnocellularis. J Neurosci 24:7514-7523. CrossRef Medline

Galea CA, Nguyen HM, George Chandy K, Smith BJ, Norton RS (2014) Domain structure and function of matrix metalloprotease 23 (MMP23): role in potassium channel trafficking. Cell Mol Life Sci 71:1191-1210. CrossRef Medline

Gao H, Lu Y (2008) Early development of intrinsic and synaptic properties of chicken nucleus laminaris neurons. Neuroscience 153:131-143. CrossRef Medline

Hamburger V, Hamilton HL (1951) A series of normal stages in the development of the chick embryo. J Morphol 88:49-92. CrossRef Medline

Hong H, Rollman L, Feinstein B, Sanchez JT (2016) Developmental profile of ion channel specializations in the avian nucleus magnocellularis. Front Cell Neurosci 10:80. CrossRef Medline

Jhaveri S, Morest DK (1982) Sequential alterations of neuronal architecture in nucleus magnocellularis of the developing chicken: a Golgi study. Neuroscience 7:837-853. CrossRef Medline

Johnson SL, Eckrich T, Kuhn S, Zampini V, Franz C, Ranatunga KM, Roberts TP, Masetto S, Knipper M, Kros CJ, Marcotti W (2011) Position-dependent patterning of spontaneous action potentials in immature cochlear inner hair cells. Nat Neurosci 14:711-717. CrossRef Medline

Jones TA, Jones SM, Paggett KC (2006) Emergence of hearing in the chicken embryo. J Neurophysiol 96:128-141. CrossRef Medline

Kandler K, Clause A, Noh J (2009) Tonototpic reorganization of developing auditory brainstem circuits. Nat Neurosci 12:711-717. CrossRef Medline

Kuba H (2007) Cellular and molecular mechanisms of avian auditory coincidence detection. Neurosci Res 59:370-376. CrossRef Medline

Kuba H, Ohmori H (2009) Roles of axonal sodium channels in precise auditory time coding at nucleus magnocellularis of the chick. J Physiol 587: 87-100. CrossRef Medline

Kuba H, Yamada R, Fukui I, Ohmori H (2005) Tonotopic specialization of auditory coincidence detection in nucleus laminaris of the chick. J Neurosci 25:1924-1934. CrossRef Medline

Kuba H, Oichi Y, Ohmori H (2010) Presynaptic activity regulates $\mathrm{Na}^{+}$ channel distribution at the axon initial segment. Nature 465:1075-1078. CrossRef Medline

Kuba H, Adachi R, Ohmori H (2014) Activity-dependent and activity- 
independent development of the axon initial segment. J Neurosci 34: 3443-3453. CrossRef Medline

Kuba H, Yamada R, Ishiguro G, Adachi R (2015) Redistribution of Kvl and Kv7 enhances neuronal excitability during structural axon initial segment plasticity. Nat Commun 6:8815. CrossRef Medline

Leao RN, Sun H, Svahn K, Berntson A, Youssoufian M, Paolini AG, Fyffe RE, Walmsley B (2006) Topographic organization in the auditory brainstem of juvenile mice is disrupted in congenital deafness. J Physiol 571:63-578. CrossRef Medline

Li D, Takimoto K, Levitan ES (2000) Surface expression of Kvl channels is governed by a C-terminal motif. J Biol Chem 275:11597-11602. CrossRef Medline

Lippe WR (1994) Rhythmic spontaneous activity in the developing avian auditory system. J Neurosci 14:1486-1495. Medline

Lippe WR (1995) Relationship between frequency of spontaneous bursting and tonotopic position in the developing avian auditory system. Brain Res 703:205-213. CrossRef Medline

Lippe W, Rubel EW (1985) Ontogeny of tonotopic organization of brain stem auditory nuclei in the chicken: implications for development of the place principle. J Comp Neurol 237:273-289. CrossRef Medline

Lu Y, Monsivais P, Tempel BL, Rubel EW (2004) Activity-dependent regulation of the potassium channel subunits Kv1.1 and Kv3.1. J Comp Neurol 470:93-106. CrossRef Medline

Manganas LN, Wang Q, Scannevin RH, Antonucci DE, Rhodes KJ, Trimmer JS (2001) Identification of a trafficking determinant localized to the Kv1 potassium channel pore. Proc Natl Acad Sci U S A 98:14055-14059. CrossRef Medline

Manley GA, Kaiser A, Brix J, Gleich O (1991) Activity patterns of primary auditory-nerve fibres in chickens: development of fundamental properties. Hear Res 57:1-15. CrossRef Medline

Nishino E, Yamada R, Kuba H, Hioki H, Furuta T, Kaneko T, Ohmori H (2008) Sound-intensity-dependent compensation for the small interaural time difference cue for sound source localization. J Neurosci 28:71537164. CrossRef Medline

Oline SN, Ashida G, Burger RM (2016) Tonotopic optimization for temporal processing in the cochlear nucleus. J Neurosci 36:8500-8515. CrossRef Medline

Ovsepian SV, LeBerre M, Steuber V, O’Leary VB, Leibold C, Oliver Dolly J (2016) Distinctive role of Kv1.1 subunit in the biology and functions of low threshold $\mathrm{K}^{+}$channels with implications for neurological disease. Pharmacol Ther 159:93-101. CrossRef Medline

Parameshwaran S, Carr CE, Perney TM (2001) Expression of the Kv3.1 potassium channel in the avian auditory brainstem. J Neurosci 15:485-494. Medline

Parameshwaran-Iyer S, Carr CE, Perney TM (2003) Localization of KCNC1 (Kv3.1) potassium channel subunits in the avian auditory nucleus magnocellularis and nucleus laminaris during development. J Neurobiol 55: 165-178. CrossRef Medline

Parks TN (1981) Changes in the length and organization of nucleus lami- naris dendrites after unilateral otocyst ablation in chick embyos. J Comp Neurol 202:47-57. CrossRef Medline

Rangaraju S, Khoo KK, Feng ZP, Crossley G, Nugent D, Khaytin I, Chi V, Pham C, Calabresi P, Pennington MW, Norton RS, Chandy KG (2010) Potassium channel modulation by a toxin domain in matrix metalloprotease 23. J Biol Chem 285:9124-9136. CrossRef Medline

Rathouz M, Trussell L (1998) Characterization of outward currents in neurons of the avian nucleus magnocellularis. J Neurophysiol 80:2824-2835. CrossRef Medline

Reyes AD, Rubel EW, Spain WJ (1994) Membrane properties underlying the firing of neurons in the avian cochlear nucleus. J Neurosci 14:53525364. Medline

Rubel EW, Parks TN (1975) Organization and development of brain stem auditory nuclei of the chicken: tonotopic organization of N. magnocellularis and N. laminaris. J Comp Neurol 164:411-433. CrossRef Medline

Salvas A, Benjannet S, Reudelhuber TL, Chrétien M, Seidah NG (2005) Evidence for proprotein convertase activity in the endoplasmic reticulum/ early Golgi. FEBS Lett 579:5621-5625. CrossRef Medline

Saunders JC, Coles RB, Gates GR (1973) The development of auditory evoked responses in the cochlea and cochlear nuclei of the chick. Brain Res 63:59-74. CrossRef Medline

Schecterson LC, Sanchez JT, Rubel EW, Bothwell M (2012) TrkB downregulation is required for dendrite retraction in developing neurons of chicken nucleus magnocellularis. J Neurosci 32:14000-14009. CrossRef Medline

Shi G, Nakahira K, Hammond S, Rhodes KJ, Schechter LE, Trimmer JS (1996) $\beta$ subunits promote $\mathrm{K}^{+}$channel surface expression through effects early in biosynthesis. Neuron 16:843-852. CrossRef Medline

Trussell LO (1999) Synaptic mechanisms for coding timing in auditory neurons. Annu Rev Physiol 61:477-496. CrossRef Medline

Tucci DL, Rubel EW (1985) Afferent influences on brain stem auditory nuclei of the chicken: effects of conductive and sensorineural hearing loss on n. magnocellularis. J Comp Neurol 238:371-381. CrossRef Medline

Vacher H, Trimmer JS (2012) Trafficking mechanisms underlying neuronal voltage-gated ion channel localization at the axon initial segment. Epilepsia 53 [Suppl. 9]:21-31.

Vacher H, Mohapatra DP, Misonou H, Trimmer JS (2007) Regulation of $\mathrm{Kv} 1$ channel trafficking by the mamba snake neurotoxin dendrotoxin $\mathrm{K}$. FASEB J 21:906-914. CrossRef Medline

Wang HC, Bergles DE (2015) Spontaneous activity in the developing auditory system. Cell Tissue Res 361:65-75. CrossRef Medline

Wang X, Hong H, Brown DH, Sanchez JT, Wang Y (2017) Distinct neural properties in the low-frequency region of the chicken cochlear nucleus magnocellularis. eNeuro 10:1523. CrossRef Medline

Watanabe T, Shimazaki T, Mishiro A, Suzuki T, Hirata H, Tanimoto M, Oda Y (2014) Coexpression of auxiliary Kv $\beta 2$ subunits with Kv1.1 channels is required for developmental acquisition of unique firing properties of zebrafish mauthner cells. J Neurophysiol 111:1153-1164. CrossRef Medline 